\title{
Communication Externalities in Cities
}

Sylvie Charlot and Gilles Duranton

November 2003 


\begin{abstract}
To identify communication externalities in French cities, we exploit a unique survey recording workplace communication of individual workers. Our hypothesis is that in larger and/or more educated cities, workers should communicate more. In turn, more communication should have a positive effect on individual wages. By estimating both an earnings and a communication equation, we find evidence of communication externalities. Being in a larger and more educated city makes workers communicate more and in turn this has a positive effects on wages. However, only a small fraction of the overall effects of a more educated and larger city on wages percolates through this channel.
\end{abstract}

Keywords: human capital, cities, communication externalities.

JEL numbers: J31, R19, and R29.

This paper was produced as part of the Centre's Globalisation Programme

\title{
Acknowledgements
}

We thank Nathalie Greenan for providing us with the COI data and Virginie Piguet for kindly matching it with location and human capital data. We are also grateful to Cécile Détang-Dessendre, Matthew Drennan, Laurent Gobillon, David Rigby, Bertrand Schmitt, conference and seminar participants at the 2002 NARSA meeting, the 2003 CEPR geography workshop in Villars, the 2003 WIDER programme meeting on spatial inequalities in Helsinki, the University of Nottingham and INRA-ENESAD for comments and suggestions. Financial support from INRA-ENESAD is gratefully acknowledged.

Sylvie Charlot is a researcher for the Institut National de la Recherche Agronomique (INRA), Dijon, France. Email contact: charlot@enesad.inra.fr Gilles Duranton is a research affiliate of the Centre for Economic Performance, London School of Economics. He is also a Senior Lecturer in the Department of Geography and Environment, London School of Economics and a research affiliate of CEPR. Email contact: g.duranton@1se.ac.uk; http://cep.1se.ac.uk/ duranton/

Published by

Centre for Economic Performance

London School of Economics and Political Science

Houghton Street

London WC2A $2 \mathrm{AE}$

All rights reserved. No part of this publication may be reproduced, stored in a retrieval system or transmitted in any form or by any means without the prior permission in writing of the publisher nor be issued to the public or circulated in any form other than that in which it is published.

Requests for permission to reproduce any article or part of the Working Paper should be sent to the editor at the above address.

(C) S. Charlot and G. Duranton, submitted 2003

ISBN 0753016702

Individual copy price: $£ 5$ 


\section{Introduction}

The strength of human capital externalities is a key determinant of the optimal subsidy to education. Furthermore, as argued by Lucas (1988) and his followers, human capital externalities could constitute a crucial engine of growth and development. Local human capital externalities are also accepted as one of the main reasons to justify the existence of cities since Marshall (1890). Hence, obtaining reliable estimates for the strength of human capital externalities is widely acknowledged to be of fundamental importance.

It is also essential to know how these externalities percolate. There are three main reasons for this. First, the literature typically infers the existence of human capital externalities indirectly by estimating a wedge between private and social returns to education. ${ }^{1}$ It speaks of human capital externality when an aggregate measure of human capital has a positive effect on individual earnings over and above that of individual characteristics. Such findings however might be driven by some missing variables and not by human capital externalities. Second, getting the optimal subsidy to education right is one thing but there could be other corrective policies. As suggested by Marshall (1890), human capital externalities may take place mostly between workers in the same city and industry through face-to-face interactions. Then fostering regular meetings within local professional associations may be a good way to improve economic efficiency. Third, without knowing how these externalities percolate, nothing prevents the theorists from assuming whatever they like. Theoretical progress is thus hampered by our lack of knowledge about the precise nature of human capital effects. ${ }^{2}$ In short, knowing how human capital externalities percolate is of considerable importance for both theory and policy.

When elaborating on 'human capital externalities', the literature almost inevitably alludes to some form of technological externalities and mentions face-to-face meetings, word-of-mouth communication, direct interactions between skilled workers, and the like. This quasi-exclusive focus on a particular sub-set of human capital externalities, which we call communication externalities, may not be warranted. Human capital could have some external effects through a variety of other channels. More human capital in a city could foster

\footnotetext{
${ }^{1}$ See for instance Rauch (1993), Acemoglu and Angrist (2000), Adserà (2000), Moretti (2000), or Simon and Nardinelli (2002). This literature is discussed more in-depth below.

${ }^{2}$ There is a long tradition in urban economics that justifies the existence of cities by an appeal to technological externalities involving direct interactions between agents (see Duranton and Puga, 2003, for a review). However, this literature offers only weak micro-economic foundations for these externalities. This difficult theoretical undertaking is made all the more difficult by the absence of evidence about how these externalities percolate, whom they concern, and at which spatial scale they take place.
} 
the supply of specialised intermediate goods and in turn improve the productivity of final producers - a pecuniary externality unrelated to communication externalities. More human capital could also lead to better matches between employers and employees. One could also invoke a more extensive division of labour within a more educated workforce, etc.

In this paper, we propose a novel attempt to identify communication externalities and distinguish them from the other external effects of human capital. To do this, we exploit a unique survey recording workplace communication practices for around 6,000 French workers in 1997. Because of its careful design and implementation, we believe this survey contains very valuable information about workplace communication. ${ }^{3}$ Our identifying assumption is that larger and/or more educated cities should favour communication as postulated for instance by Beckmann (1976), Borukhov and Hochman (1977), Fujita and Ogawa (1982), Black and Henderson (1999), Glaeser (1999), Berliant, Reed and Wang (2001) or Lucas (2001) among others. Then it should also be the case that more communication should have a positive impact on individual earnings (Jovanovic and Rob, 1989, and the references above). The strength of communication externalities can then be computed as the effects of city size and average urban schooling on communication times that of communication on earnings.

Consistent with our two hypotheses, we find that workplace communication is positively associated with earnings and that city size and average urban schooling are positively associated with workplace communication. However, in total only about a tenth of the effects of city size and average urban schooling appear to percolate through communication externalities. This suggests that the bulk of the effects of city size and average urban schooling on earnings, which are sizeable and highly significant, must percolate through channels other than communication externalities.

With respect to the strength of communication externalities, these findings may be biased downwards because we can only observe the amount of communication and not its quality. If larger and more educated cities allow for better rather than more communication, we may underestimate the strength of communication externalities. However, these unobservable quality effects would need to be very large to justify communication

\footnotetext{
3 'Communication externalities' is one of those topics like social capital for which finding 'market data' that leave reliable paper trails appears hopeless. For the time being, progress on this type of topics may have to rely on survey data and experiments.
} 
externalities being quantitatively of primary rather than secondary importance. ${ }^{4}$ On the other hand, our findings about communication externalities may be biased upwards because of workers' unobserved heterogeneity. If high-wage cities attract good communicators, we may overestimate the strength of communication externalities. To investigate this issue, we use information about the worker's birthplace to distinguish between 'movers' and 'stayers' in separate regressions. We also instrument the characteristics of current worker location by location and family characteristics at birth. Overall, we find some evidence of spatial sorting but they do not alter the general flavour of our results.

As a further concern, workplace communication could be suspected of being determined simultaneously with earnings. For instance, when a worker is promoted to a higher position, this is likely to involve both a higher wage and more workplace communication. To investigate this, one would like to have variables that determine workplace communication but remain un-correlated with the residual in our earnings equation. Fortunately our survey data contains a wealth of information about the workplace and the working conditions of the surveyed workers. Some of the variables related to these issues provide good instruments for workplace communication. Using these instruments leaves our results mostly unchanged.

Three important limitations must be acknowledged. First, our data regards communication at the workplace only. We thus ignore potentially important effects of communication happening in social networks. These may help workers find jobs, learn about business opportunities, etc. Second, we only measure static communication externalities and not the kind of long-run learning benefits provided by the cities that are highlighted by Glaeser and Maré (2001). Third, we measure communication externalities only at the city level and not at the country level. ${ }^{5}$ It is however natural to expect communication externalities to be strongly localised. Bearing these caveats in mind, our general conclusion is that communication externalities are present in cities. However only a small fraction of the external effects of human capital percolate through communication.

\footnotetext{
${ }^{4}$ Besides, it is not fully clear how large cities could offer massively better commu nication without workers communicating much more to benefit from these quality advantages. In other words, large quality effects should be captured by larger equilibrium volumes of communication.

5 See Cohen and Soto (2001) for a recent cross-country attempt to measure social returns to education and a discussion of the macro literature. In this literature, the pendulum is fast moving between two extremes that view the role of human capital as either fundamental or negligible. Cohen and Soto (2001) argue that much of the disagreement finds its source in bad data. In their work, they use better data and claim that social and private returns to education are essentially equal. However, in their regression, they use the rate of urbanisation as control to proxy for total factor productivity. This variable may however also capture human capital externalities taking place in cities.
} 
The strategy of the rest of the paper is the following. The next section reviews some relevant empirical literature. Section 3 presents a theoretical model to illustrate the identification issues discussed above. Section 4 provides some estimation results for our model. Section 5 performs a series of robustness test. Section 6 draws some conclusions.

\section{Related Empirical Literature}

Our paper is related to three main strands of literature. First, using Roback (1982)'s equilibrium location approach, Rauch (1993) estimates hedonic earnings equations by regressing individual earnings on a set of individual controls together with city level variables. Despite numerous controls for individual and city characteristics, he finds a strong effect of average schooling on individual earnings within US cities. This finding has been replicated many times (e.g., Adserà, 2000, Simon and Nardinelli, 2002, etc). According to this type of estimation, external returns to education in cities could be very large, between 50 and $100 \%$ of the private returns.

Rauch's seminal approach has been criticised on several grounds. Cross-section estimations make it difficult to distinguish human capital externalities from the effects of unobserved city heterogeneity whereby 'high-wage' cities might attract high-education workers. A second concern regards individual unobserved heterogeneity. If workers with good unobserved characteristics tend to locate in high-education cities, the estimates for external returns to human capital obtained in a Rauch-style regression are again biased upwards. ${ }^{6}$

To deal with these issues, instrumental variables have been considered. A good instrument for average schooling would affect the schooling of the majority of workers in a given location without being correlated with local wages. Acemoglu and Angrist 2000) argue that differences in school compulsory attendance laws and child labour laws in US states over the $20^{\text {th }}$ century provide such variation, at least for secondary education. In their preferred estimation, they obtain very small external returns to education. In the same spirit but using different instruments for schooling, Moretti (2000) shows that the share of college graduates in a city has a strong effect on individual earnings. These results are confirmed when using the longitudinal dimension of a panel of workers.

\footnotetext{
${ }^{6}$ In the same vein, it could be the case that cities with higher wages provide more schooling.
} 
A more fundamental critique to Rauch's approach has been recently put forward by Ciccone and Peri (2002). It builds on a well-known fact: workers are imperfect substitutes in production (see Topel, 1997, for a recent overview) so that unskilled wages are typically expected to be higher in cities where the relative supply of skilled workers is larger. In other words, without accounting for imperfect substitutability between different types of workers, human capital externalities may be mistaken for complementarities in production. Ciccone and Peri (2002) develop a novel approach to assess the effects of an increase in human capital in a city keeping the skill composition of the workforce constant. Applying this 'constant composition' methodology to US cities, they find small and insignificant human capital externalities.

We differ from this literature (see Moretti, 2003, for a survey) in our use of workplace communication data to directly identify communication externalities, a sub-set of human capital externalities. Unlike the aforementioned papers, our primary interest is not to provide a better measure of total external returns to education. The novelty in this paper is that we focus on workplace communication. That is, we concentrate on one particular channel for human capital externalities that figures prominently in our thinking about cities. In this regard, our approach is related to the small literature attempting to identify the sources of urban increasing returns.

Only a few papers attempt to disentangle empirically between different microfoundations of urban increasing returns. ${ }^{7}$ Exemplary in this literature, Holmes (2002) uses the differences in the location patterns of sales offices of small vs. large firms. This allows him to separate the effects of local market size from those of cost-reducing externalities and comparative advantage. Building on Jaffe, Trajtenberg and Henderson (1993), Almeida and Kogut (1999) show that the citation trail for patents coincides with the movement of key scientific personnel. This suggests that 'spillovers' may be channelled through the labour market rather than word-of-mouth communication between scientists. In a different vein, Dumais, Ellison and Glaeser (1997) use carefully constructed proxies to distinguish between the three Marshallian motives for agglomeration. They also find support for thick local labour market effects.

Finally, although the terminology may differ, communication externalities enjoy widespread popularity and attention among other social scientists. Saxenian (1994) is a good example of this type of work. She forcefully argues that the root of Silicon Valley's success

\footnotetext{
${ }^{7}$ See Rosenthal and Strange (2003) for a more complete survey of this literature. For a more general discussion of identification problems raised by non-market interactions, see Manksi (1993) and Brock and Durlauf (2001).
} 
are to be found in a unique culture that favours frequent and open face-to-face contacts, which in turn lead ideas to flow freely across workers and firms. This literature is discussed at length in Storper (1997) who reviews a large body of work offering suggestive evidence about communication externalities. Unfortunately this literature relies mostly on qualitative evidence and the importance of communication externalities is never quantitatively assessed. ${ }^{8}$

\section{Communication Externalities Vs. Other Human Capital Effects in Cities}

The first objective of the model that follows is to show that not all human capital externalities can be interpreted as communication externalities. Instead more human capital in a city can a priori generate both stronger communication externalities and stronger other human capital externalities unrelated to communication, which we nodel here through an input sharing mechanism. ${ }^{9}$ This model also shows how communication externalities can be empirically distinguished from these other human capital externalities by deriving some equations that can be estimated.

\subsection{Urban scale effects unrelated to communication externalities}

The first part of our model follows Ethier's (1982) production-side version of Dixit and Stiglitz's (1977) model of monopolistic competition. This model was first embedded in an urban framework by Abdel-Rahman (1988), Fujita (1988) and Rivera-Batiz (1988).

Final good producers use intermediate goods produced by differentiated suppliers to produce a homogenous consumption good under constant returns to scale. This final good, which also serves as numéraire, can be traded across cities at no cost. By contrast, intermediates cannot be traded across cities so that final good producers can only buy from intermediate producers located in the same city. Final producer $k$ in city $i$ produces according

\footnotetext{
${ }^{8}$ Of particular interest in this body of work, Goddard (1973) and Goddard and Morris (1976) compile very detailed communication data about a large group of workers in London. They show a strong link between the intensity of communication and central locations. They also document a wealth of interesting features about workplace communication. Unfortunately they do not explore the links between communication and productive efficiency.
} 
to:

$y_{k}=\left[\int_{z \in i} q_{k}(z)^{(\sigma-1) / \sigma} \mathrm{d} z\right]^{\sigma /(\sigma-1)}, \sigma>1$

where $q_{k}(z)$ is the quantity of intermediate $z$ bought by $k, \sigma(>1)$ is the elasticity of substitution across intermediates, and the notation $z \in i$ denotes any (intermediate producer) $z$ located in city $i$. After denoting by $p(z)$ the price of intermediate $z$, final producer $k$ 's profit is given by:

$$
\pi_{k}=y_{k}-\int_{z \in i} p(z) q_{k}(z) \mathrm{d} z
$$

As in Ethier (1982), intermediate goods are produced by monopolistically competitive firms. To produce any variety of intermediates, there is a fixed labour overhead to start production and a constant quantity of labour is needed for each marginal unit. Employment in firm $z$, expressed in effective units of labour, is thus:

$l(z)=\beta q(z)+\alpha$

After denoting by $w_{i}$ the wage rate in city $i$, the profit function of intermediate producer $z$ in city $i$ is:

$\pi(z)=p(z) q(z)-w_{i}[\beta q(z)+\alpha]$.

To solve the model, note first that profit maximisation by final producer $k$ (equation 2) implies:

\footnotetext{
${ }^{9}$ We build on a specific model wherein input sharing between final producers implies increasing returns at the city level. Similar results can be obtained with any alternative source of local increasing returns that does not rely on communication externalities. See Duranton and Puga (2003) for a survey of the different microeconomic foundations of urban increasing returns. Our preference for input-sharing as opposed to, say, matching is that the former mechanism naturally benefits all workers symmetrically whereas it is more difficult to conceive how a larger fraction of skilled workers in a city could help the matching of unskilled workers to jobs.
} 


$$
p(z)=\frac{q_{k}(z)^{-1 / \sigma} y_{k}}{\int_{z \in i} q_{k}(z) \mathrm{d} z} .
$$

Since, intermediates cannot be traded across cities, summing over all final producers in the city yields the inverse-demand faced by intermediate producer $z$. This can be inserted into the profit of $z$ given by (4). Profit maximization by intermediate producers then implies that the price of intermediates, $p(z)=\sigma \beta w_{i} /(\sigma-1)$, is a mark-up over marginal cost and is independent of total market size. Then under free entry in the production of intermediates, the output of any intermediate producer is independent of market size: $q(z)=\alpha(\sigma-1) / \beta$. After denoting by $L_{i}$ total effective labour supply in city $i$, total output is then given by:

$$
Y_{i}=\frac{(\sigma-1)}{\alpha^{1 /(\sigma-1)} \beta \sigma^{\sigma /(\sigma-1)}} L_{i}^{\sigma /(\sigma-1)} \equiv \Phi L_{i}^{\sigma /(\sigma-1)} .
$$

Finally clearing on the labour market and free entry for final producers imply that final output is fully dissipated in the wage bill. This yields the following wage rate:

$$
w_{i}=\Phi L_{i}^{1 /(\sigma-1)} .
$$

This wage increases with city size. A larger workforce in a city leads to a wider range of intermediates being produced for final good production. Since these intermediates enter the production function of final good producers with the same constant elasticity of substitution $\sigma$, a wider range of intermediates results in final output rising more than proportionately. Hence, despite constant returns to scale at the firm level in final production, there are aggregate increasing returns working through this pecuniary externality. The strength of these aggregate increasing returns decreases with $\sigma$, the elasticity of substitution between intermediates. To summarise, in this model, which is arguably the canonical model of agglomeration economies, local increasing returns arise from sharing a greater variety of intermediates by final producers as the local market expands. 


\subsection{Human capital in cities}

The effective labour supply of worker $j$, denoted $l_{j}$, is a function of her human capital, $h_{j}$. Then, aggregate effective labour supply in city $i, L_{i}$ is the sum of the effective labour supply of all workers living in the city. Specifically:

$L_{i}=\sum_{j \in i} l_{j}$, where $\quad l_{j}=e^{h_{j}}$

In turn, the human capital of worker $j$ living in city $i, h_{j}$, is a function of her measured skills such as those accruing from education and labour market experience, $s_{j}$, her volume of communication, $x_{j}$, and some unobserved productivity shock, $\varepsilon_{j}$ :

$h_{j}=\delta s_{j}+\gamma x_{j}+\varepsilon_{j}$

The idiosyncratic shocks, $\varepsilon$, are assumed to be normal and iid. The basic justification for the specification in (9) is that a worker's productivity depends not only on her observed skills (education, experience, etc) but also on the informal knowledge and information she receives when communicating and some unobserved random component (such as a temporary productivity shock or some unobserved abilities). ${ }^{10}$

The labour market earnings of worker $j$ living in city $i, W_{j}$ are equal to $w_{i} l_{j}$. After inserting (8) and (9) into (7), we obtain:

$W_{j}=\Phi\left(\sum_{g \in i} e^{\delta s_{g}+\gamma x_{g}+\varepsilon_{g}}\right)^{1 /(\sigma-1)} e^{\delta s_{j}+\gamma x_{j}+\varepsilon_{j}}$.

\footnotetext{
${ }^{10}$ Observation and imitation may also provide a channel for increasing human capital. For most skilled occupations, we expect this channel in its pure form to be of trivial importance. Instead we expect observation and imitation to be combined with communication. Note also that skills and communication are perfect substitutes in the production of human capital but they complement each other when it comes to effective labour supply. Using (8) and (9), it is easy to verify that: $\partial^{2} l_{j} / \partial s_{j} \partial x_{j}>0$.
} 
When $\delta s$ and $\gamma x$ are small, a Taylor expansion implies

$$
\log W_{j} \approx \log \Phi+\frac{1}{\sigma-1}\left(\log N_{i}+\delta \bar{s}_{i}+\gamma \bar{x}_{i}+\bar{\varepsilon}_{i}\right)+\delta s_{j}+\gamma x_{j}+\varepsilon_{j}
$$

where $N_{i}$ is the population in city $i$. By the law of large numbers $\bar{\varepsilon}_{i}=0$ so that $\delta \bar{s}_{i}+\gamma \bar{x}_{i}$ is the average human capital in city $i$. According to (11), individual earnings increase with the individual effective labour supply. In turn, the latter is determined by individual characteristics (i.e., skills, $s_{j}$, communication, $x_{j}$, and the unobserved random component, $\varepsilon_{j}$ ). At the same time, earnings are also influenced by city aggregates. Because of input sharing, earnings are higher in cities where aggregate effective labour supply is higher, that is where workers are more numerous, more skilled, and communicate more (i.e., higher $N_{i}, \bar{s}_{i}$, and $\bar{x}_{i}$ respectively). ${ }^{11}$

\subsection{Communication externalities in cities}

The theoretical literature on externalities in cities proposes a variety of mechanisms to explain why cities may foster communication externalities. Glaeser (1999) and Berliant, Reed and Wang (2001) explicitly assume that larger cities offer more opportunities for face-to-face meetings --- a population size effect. Jovanovic and Rob (1989) and many others suggest that during face-to-face interactions, skilled workers learn more from other skilled workers than from unskilled workers. Hence holding the number of meetings fixed, a more skilled workforce provides better learning opportunities --- an average human capital effect. Combining the two effects, larger and more educated cities are widely assumed to increase workplace communication and in turn to raise wages.

However, we cannot expect workplace communication to be influenced only by city level variables. First, some workers may be better at communicating because of their better measurable skills (viz. reading, writing, etc). Furthermore, social skills may foster one's

\footnotetext{
${ }^{11}$ Previewing some estimation issues, note that we assume that cities differ only in their average human capital and their population size. The effects of exogenous productivity differences between cities (i.e., differences in $\Phi)$ and spatial sorting of workers with respect to their unobserved characteristics (i.e., $\bar{\varepsilon}_{i} \neq 0$ ) are discussed in Section 5. We also bear in mind that in small cities, the number of observations may be small so that the approximation $\bar{\varepsilon}_{i}=0$ given by the law of large numbers may be invalid. This may then generate some heteroscedasticity in our results.
} 
abilities to extract information during face-to-face communication, to put forward ideas in small-group meetings or to generate loyalty from colleagues, subordinates, employers, etc. The simplest specification is to assume that personal workplace communication of worker $j$ in city $i$ is given by:

$x_{j}=A+B \cdot \log N_{i}+C \cdot \bar{s}_{i}+D \cdot s_{j}+\mu_{j}$.

where $A$ is a constant, $B$ is a coefficient measuring the elasticity of individual workplace communication with respect to city size, $C$ measures the effect of average skills in city $i$, and $D$ is the effect of individual (measured) skills. The $\mu$ capture individual unobserved social skills, which are assumed to be iid and normally distributed. ${ }^{12}$ Workers with better skills (measured, $s_{j}$, or social and unobserved, $\mu_{j}$ ) are expected to communicate more. Workers located in larger and/or more educated cities are also expected to communicate more because of more people to meet and higher quality meetings. ${ }^{13}$ In this sense, we speak of communication externalities.

Inserting (12) into (11), we obtain,

$\log W_{j} \approx$ constant $+\frac{\delta+\sigma B}{\sigma-1} \log N_{i}+\frac{\gamma+\sigma C}{\sigma-1} \bar{s}_{i}+(1+D) s_{j}+\varepsilon_{j}+\mu_{j}$

This reduced form is such that the earnings of worker $j$ increase when she has better measured skills, $s_{j}$, when she has better social skills $\mu_{j}$ and better unobserved productive skills, $\varepsilon_{j}$, when she lives in a larger city and when she lives in a city with more skilled workers. The effects of city size and average schooling percolate through two different channels (partly nested into each other). First, a larger and/or more educated city implies stronger communication externalities, which in turn lead to more higher human capital and thus higher earnings. Second, a larger and/or more educated city also implies stronger

\footnotetext{
${ }^{12}$ We model the effects of the environment on workplace communication as a pure externality. More subtle (and realistic) mechanisms may be considered. In particular, workers may play a less passive role and decide how much time they want to communicate depending on where they are. With the data we have, unfortunately these issues are beyond the scope of this paper.

${ }^{13}$ Again, previewing some estimation issues, note that we still consider that cities only differ in their skill composition and their population size. Our specification also assumes that the unobserved social skills are iid across cities. These two assumptions are discussed further in Section 5 .
} 
externalities unrelated to communication like those caused by input sharing. They also lead to higher earnings.

Estimating directly (13), which is similar to what is estimated by Rauch (1993) and his followers, would not allow us to identify communication externalities. To identify such effects and distinguish them from the other external effects of human capital, our empirical strategy is to estimate (11) and (12) instead of estimating only the reduced form (13). To do this, data about workplace communication is obviously needed.

\section{Data and Results}

\subsection{Data}

In what follows, we exploit data from a detailed survey conducted in 1997 in France. 8812 workers were randomly drawn from the labour force employed in manufacturing, services (accounting only) and retail (Do-It-Yourself chains only). Selected workers were individually interviewed and the information was matched with corresponding firm level data, other individual data, and location data. For each worker who responded to the survey and whose data could be matched with wage and location data, we know their responses to around 80 questions covering a wide range of topics: working conditions, organisational change, workplace communication and information technologies, workplace location (rural, suburban, or urban with the city population), earnings, and industry.

This data, further described in Appendix, is critically analysed in Greenan and Hamon-Cholet (2001a, b) and Greenan and Mairesse (1999) who offer various checks regarding its quality. A key part of the questionnaire regards around 20 questions related to the workplace communication of the surveyed workers. A first sub-set of questions is about communication within the firm. A second sub-set of questions regards communication external to the firm. Finally the last sub-set of questions is concerned with the media used by the surveyed workers. In this paper, we aggregate individual answers to all these questions into synthetic communication indices whose construction is explained in Appendix. ${ }^{14}$

Before going any further in the analysis it is worth pausing to assess what can be learnt from our data. Our assessment is that such communication data despite obvious

\footnotetext{
${ }^{14}$ In a companion paper (Charlot and Duranton, 2003), we explore the details of the answers to these questions.
} 
drawbacks contain valuable information about workplace communication. Note that the questions about whom the workers communicate with speak about "instructions", which are defined as "important information given or received on a regular basis and are necessary for the conduct of your work". Gossiping around the coffee machine does not constitute giving or receiving instructions. Instead meeting with a consultant with a view to solving a problem or asking a colleague how to operate a machine does. Hence part of the communication detected in the survey should reflect the circulation of knowledge that is crucial for the accumulation of human capital. We also expect the questions about the different media to reflect this.

However the survey is also severely limited by how far we can describe and characterise workplace communication. First, we know nothing about the destination of the communication. We know with whom workers communicate with but not where these other workers are: direct colleagues are very likely to be in the same location whereas customers and suppliers may not. Then, there is only one question about the intensity of communication. This is very limiting because this question is framed in a particular context (communication with customers using face-to-face or telephone). The last imitation regard the diversity of persons with whom communication takes place. This issue plays a crucial role in the model described above (and more generally in our thinking about the communication advantages of large cities). Unfortunately there is no question in the questionnaire to inform it.

\subsection{Econometric specification}

To estimate our earnings equation (11), we need to proxy workers' skills by a set of observable characteristics. This implies the following econometric specification:

$$
\begin{aligned}
& \log W_{j}=a+b_{1} \cdot \text { Gender }_{j}+b_{2} \cdot \text { Educ }_{j}+b_{3} \cdot \text { Age }_{j}+b_{4} \cdot \text { Age }_{j}{ }_{j}+b_{5} \cdot \text { Com }_{j} \\
& +c_{1} \cdot \text { Urban }_{j} \times \log \text { Pop }_{i}+c_{1^{\prime}} \cdot \text { Suburb }_{j}+c_{1^{\prime \prime}} \cdot \text { Rural }_{j}+c_{2} \cdot \text {. }_{\text {hareGraduate }}+c_{3} \cdot \text {.meanCom }_{i}+\varepsilon_{j} .
\end{aligned}
$$

In equation (14), the (natural) log of the earnings of each worker is regressed on a set of personal characteristics together with a set of city characteristics corresponding to our theoretical specification. The variables Gender, Educ, Age and Age2 are standard proxies for individual skills in earnings equations. Education is measured by 6 dummies for educational 
attainment. ${ }^{15}$ Age and its square proxy for labour market experience, which is unknown. ${ }^{16}$ Com is our main index of individual workplace communication. It ranges from 0 to 100 . We also use a set of location characteristics. Because population is unknown for rural and (remote) suburban location, we introduce 3 dummy variables Urban, Suburb, and Rural for workers located in urban, suburban and rural areas respectively. For urban areas, we proxy the city workforce, $N_{i}$, by total city population, $P_{o p}$ (which is interacted with the Urban dummy). The average skill level in an area is measured by the share of college and university graduates, our two highest educational attainments. Finally we construct an index of average city communication, meanCom, from our individual communication data. It also ranges from 0 to 100. See the Appendix for more details on this index.

There are two main differences between (14) and the standard human capital framework. First we introduce workplace communication (Com) as another individual determinant of earnings. Second, to capture the external effects of aggregate labour supply highlighted in (11), equation (14) also estimates three coefficients $c_{1}, c_{2}$ and $c_{3}$ relating to population, the share of graduates, and aggregate communication in each location. ${ }^{17}$

Turning to the communication equation (12), our econometric specification is:

$$
\begin{aligned}
& \text { Com }_{j}=A+B_{1} \cdot \text { Gender }_{j}+B_{2} \cdot \text { Educ }_{j}+B_{3} \cdot \text { Age }_{j}+B_{4} \cdot \text { Age }^{2}{ }_{j}
\end{aligned}
$$

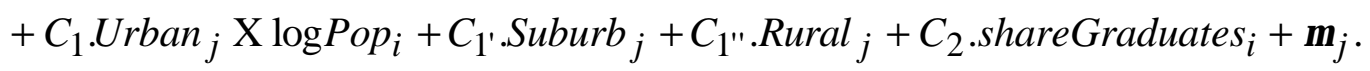

In this equation, we proxy for individual skills, the city workforce and average schooling as in the earnings equation. The two specifications (14) and (15) have a number of potential pitfalls, which are discussed in the next section. Before discussing them, we first present our basic OLS results.

\footnotetext{
${ }^{15}$ Educl corresponds to university graduates (with at least three years of higher education), Educ2 denotes college graduates (two years of higher education), Educ3 is for high-school graduates, Educ4 is for graduates from vocational schools, Educ5 is for junior high-school graduates, and Educ6 (our reference) corresponds to the absence of degree. See the Appendix for more details .

${ }^{16}$ Since we know only the educational attainment and not the number of years of education, we cannot proxy labour market experience in the usual way (i.e., age - number years of education - 5). Note that this variable will capture not only the effects of experience but also cohort effects, etc. This need not worry us because the structural interpretation of the coefficient on this variable is not of fundamental importance here.

17 Note that we do not use employment in the firm or establishment where the worker is employed as explanatory variable here (see instead, Charlot and Duranton, 2003). The main reason is that what this variable captures is rather unclear (worker unobserved ability or a real firm effect?). Furthermore, this variable is missing for many observations.
} 


\subsection{Earnings equation: OLS results}

Column 1 of Table 1 is our preferred specification for the earnings equation (14) since it is the one that matches most closely our theoretical specification (equation 11). The effects on earnings (or wages for that matter since we consider annualised earnings for full-time employees) of the standard individual variables (gender, education, age and its square) are in line with what is usually obtained in this type of exercise. There is no need to comment on them further. The first novel feature in this estimation regards the magnitude of the coefficient on individual communication. A one-point increase in the communication index on scale from 0 to 100 corresponds to a wage increase of $0.46 \%$. More tellingly perhaps, a one-standard-deviation increase in the communication index (21.3 points) corresponds to a wage increase of about $10 \%$. This effect is large and highly significant.

The effect of city size is in line with previous results in the literature (albeit in the lower tier of existing estimates): an increase of $1 \%$ in city size corresponds to a wage increase of $1.019 \%$. This corresponds to scale economies of around $2 \% .{ }^{18}$ The coefficient on mean city communication is only weakly significant and its magnitude is around one fourth of that on individual communication. Finally, the coefficient on the share of college and university graduates is large like in all previous estimates using this variable (Rauch 1993, Adserà 2000, Moretti, 2000 and 2002, etc). A one percentage point increase in the share of university and college graduates in a city of corresponds to a $0.5 \%$ increase in wages for all workers in this city. Stated differently, the measured external returns on college and university education are roughly of the same magnitude as the measured private returns. ${ }^{19}$ Note however that the correlation between the log of population and the share of graduates across urban areas is highly significant and quite high at 0.53 . Hence the coefficient on the share of graduates may be capturing some of the effects of city size (and conversely). ${ }^{20}$

Columns 2-6 of Table 1 report results for similar estimations where one or more city level explanatory variables are left aside. They confirm the basic findings of Column 1

\footnotetext{
18 The coefficient for the rural dummy is at 0.205 and the reference is a city of unit size. This implies that with a coefficient on $\log$ city population at 0.192 , communication in rural areas is the same as in cities of around 30,000 .

19 We do not know in which proportions innate abilities and educational inputs determine educational attainment. This issue is of secondary importance in our analysis because our model takes educational attainments as given and tries to estimate their external effects going through communication. However, any fully thought through policy attempting to make individuals internalise human capital externalities will require a precise answer to this question.

20 This fact is usually ignored in the literature on human capital externalities where city size is typically measured in levels and not in logs if at all.
} 
regarding the importance of individual communication, that of city size, that of the share of graduates and the mixed results for average communication. The very large coefficient on the share of graduates in Column 4 where city size is omitted confirms the strong collinearity between these two variables. Finally, Column 6 of Table 1 is a standard earnings equation with no city level variable and no individual communication. Note that individual communication has an important independent effect: the $\mathrm{R}^{2}$ goes up by five percentage points when individual communication is added to a standard earnings equation (see Columns 5 and $6)$.

Table 2 reports the results of another series of earnings regressions, this time adding more controls. There are two reasons for doing this: robustness and comparison with the results of Rauch (1993) and his followers who use extensive sets of controls for individual and city characteristics. Adding further controls only marginally increases the explanatory power of the regressions. The $\mathrm{R}^{2}$ increases from $49 \%$ in our preferred specification to $51 \%$ when introducing family, sectoral and occupational controls. With respect to the four coefficients of interest (on individual communication, city population, mean communication and mean education), the changes are small. The effect of individual communication remains strong and very significant. Adding family, sectoral and occupational controls reduces the coefficient on individual communication by at most $15 \%$. The coefficient on city population is reduced by around a fifth and it remains highly significant. Interestingly, these extra controls increase the coefficient on mean city communication and improve its significance. With all the extra controls, this coefficient is now significant at $5 \%$ whereas in Table 1 it is significant at $10 \%$ in only one specification. The coefficient on the share of graduates is mostly unchanged. Overall these results reinforce our previous findings.

In regressions not reported here, we also used city population instead of its log as is common in the literature. In this case, the coefficient on city size is very small but significant and the impact on the other coefficients (apart from the share of graduates) is minimal. We also ran our regressions using different classes of city size instead of log population with no sizeable change. To test the robustness of our communication index, we ran the regressions reported in Table 1 and 2 using two alternative communication indices. ${ }^{21}$ Again the differences were minimal. Finally, we re-estimated our regressions with robust standard errors as well as clustered standard errors. This is because we are using city aggregates as explanatory variables in a micro-data estimation. As highlighted above, this may create some

\footnotetext{
${ }^{21}$ Again see the Appendix for details.
} 
heteroscedasticity. However, the estimated robust standard errors and clustered standard errors are close to those obtained by OLS - typically about $10 \%$ larger.

To conclude on the earnings equation, it is worth noting that despite the presence of communication variables, our results here are not very different from those obtained in the literature. Because he is also using the share of graduate to capture the external effects of human capital, we can compare directly our results with those of Moretti (2000) who uses US wage data and Moretti (2002) who is doing a similar exercise with production functions. We find that a one point increase in college graduates increases wages between $0.5 \%$ and $0.9 \%$ whereas Moretti (2000) obtains estimates ranging between $0.4 \%$ and $1.9 \%$ and Moretti (2002) is between $0.4 \%$ and $0.9 \%$ for output per worker. Because they are using different variables, a direct comparison with Rauch (1993), Adserà (2000), or Simon and Nardinelli (2002) is more difficult. Nonetheless, they also find external returns to education being between $30 \%$ and $100 \%$ of the private returns.

\subsection{Communication equation: OLS results}

To explore the determinants of individual workplace communication, the latter is regressed on a set of individual characteristics and a set of city level variables. ${ }^{22}$ Note first that because the residuals in our two equations are a priori not correlated, it is legitimate to use another OLS.

Column 1 of Table 3 is our preferred specification for the communication equation (15) because it offers the closest match with our theoretical specification (equation 12). Looking first at the coefficients on the individual characteristics, we find evidence of a communication gender gap. The communication score of women is about 3.9 points below that of men. Given that the mean communication score is around 37, the relative communication gap between men and women is around $10 \%$. This is less than the earnings gender gap, which is around 20\%. In view of the results of Columns 4 and 5, this gender coefficient does not proxy for sectoral or occupational differences. Quite the contrary, the gender communication gap increases when these controls are introduced (see Columns 3 and 4).

The coefficients on educational attainments show that education is a strong determinant of workplace communication. The difference between university and high-school

\footnotetext{
${ }^{22} \mathrm{We}$ are not aware of any similar analysis in the literature. The only exception is Gaspar and Glaeser (1998) who regress a few city level communication variables on city characteristics.
} 
graduates (i.e., Educl and Educ3) is 14 points whereas that between high-school graduates and dropouts with no degree is even larger at 24 points (i.e., more than one standard deviation). As shown by Columns 3 and 4, only a small part of this gap is accounted for by sectoral and occupational dummies. There is also evidence of a small age effect. An extra year of age at 20 increases communication by 0.6 point. At age 40 , the increase is smaller: 0.15 points. Communication peaks at around 50 years, slightly before earnings.

Turning to city level variables, we find first a significant but small effect of city population. Moving from a city with a population of 10,000 to one with 5 million corresponds to an increase in the individual communication score of 2.4 points. Regarding the share of college and university graduates, we again find a significant but small effect. Workers in a city with twice the national share of graduates (i.e., 30\% instead of $15 \%$ ) see their communication score increase by 2 points. Hence both city size and average urban schooling have a positive effect on communication. However these effect are small --- much smaller than the direct effects of city size and average schooling on wages. This is our main finding.

Column 2 of Table 3 reports results when mean city communication is added as explanatory variable. The coefficient on this variable is highly significant and the coefficient on city size becomes insignificant. This could be because workers communicate more in environments where there is more communication, a feature ignored by our theoretical specification. However, we must remain cautious here because the meanCom is constructed by aggregating individual observations. As a result, this variable is correlated with individual communication in small cities where the number of observations is low.

Adding sectoral dummies (Column 3) to the preferred estimation changes close to nothing. By contrast, adding occupational dummies (Column 4) makes the city level variables less significant or not significant at all. This was to be expected because managerial occupations in which workers communicate a lot are overwhelmingly located in large and highly educated cities. However, occupation and location could well be jointly determined making the interpretation of Column 4 problematic. Even when accepting the results in this column at face value, one would need to explain why high-communication positions tend to be disproportionately located in larger and more educated cities. More generally, it is worth noting that a 'full ceteris paribus' is not desirable here. We expect communication intensive jobs to be unevenly distributed across industries, firms and occupations. Communication intensive jobs are also expected to be located in larger cities. Controlling for all the features that explain communication and determine location at the same time is not likely to be very 
enlightening to the extent that these could be the two sides of the same coin. ${ }^{23}$ Finally we also estimated these regressions with robust standard errors. As with the earnings regression, the differences in the standard errors with standard OLS estimates are small.

The main conclusions we draw from Table 3 are the following. The local environment matters to determine individual communication but the effects are small - much smaller than in the earnings equation. We also find that individual communication is fairly well explained by individual characteristics (gender, age, and education). However, the $\mathrm{R}^{2}$ are on average below those obtained in the earnings equations, hinting at the mportance of unobserved social skills $\left(\mu_{j}\right)$.

What about the effects of communication externalities on earnings? Using the Columns 1 of Tables 1 and 3, a log point increase in city population increases individual communication by 0.385 . This in turn implies an increase of $0.385 \times 0.00458=0.00176 \log$ point for the wage. This corresponds to a wage increase of about $0.18 \%$. At the same time, the direct coefficient on city size in the earnings equation is about ten times as large at $1.9 \%$. Turning to the share of university and college graduates, a percentage point increase in the local fraction of graduates increases communication by 0.131 , which implies a wage effect of $+0.06 \%$. The direct coefficient of the share of graduates in the earnings equation is about 8 times as large. When calculating their standard errors, both coefficients are significant at $5 \%$. Hence communication externalities appear to take place in cities but they are small. About one tenth of the benefits of city size percolate through communication. ${ }^{24}$ Turning to the external returns to education, again around $12 \%$ of them only seem to pass through communication. Stated differently, the external returns to education mediated by communication correspond to around $10 \%$ of the private returns.

\footnotetext{
${ }^{23}$ For instance assume the existence of 'blue' jobs subject to weak communication externalities and 'white' jobs subject to strong communication externalities. With communication fostered by city size and the cost of workers also increasing with city size, in equilibrium we expect white jobs to be located in large cities and blue jobs to be located in small cities. Controlling for the 'colour' of jobs would not be very helpful in this model. More generally, a more complete test of communication externalities would involve a theory of and data about the location of jobs. This is beyond the scope of this paper. In absence of an equation for the location of jobs, a full ceteris paribus is not desirable.

${ }^{24}$ There is also an indirect effect of these communication externalities. A greater share of graduates and/or a larger population increase the human capital of all workers through communication externalities. In turn a larger human capital has a positive effect on output through the other externalities. This indirect (or combined) effect is however very small because the effects of average communication are only about a quarter of those of individual communication.
} 


\section{Estimation Issues and Robustness Tests}

Estimating equations (14) and (15) with simple OLS raises a series of estimation issues that need to be discussed. They regard the imperfect substitutability across workers with different skills, the spatial sorting of workers, the possible endogeneity of communication, city size, and education. Let us discuss them in turn.

\subsection{Imperfect substitutability across workers}

As highlighted by Ciccone and Peri (2002) and Moretti (2000 and 2003), the wage of unskilled workers can increase with the relative supply of skilled workers for reasons unrelated to human capital externalities. In fact, for average wages to increase with the relative supply of skilled workers, we only need skilled and unskilled workers to be imperfect substitutes in the local production function (instead of perfect substitutes as assumed in the model). Put differently, a positive coefficient on the share of graduates could reflect imperfect substitutability across workers rather than some external effects of human capital.

Such imperfect substitutability also implies that the wage of skilled workers should decrease with their relative supply. Like Moretti (2000), it is possible to re-run our basic regressions but using only observations relating to university educated workers. If the coefficient on the local share of university graduates is still positive, this implies that the positive effect of human capital externalities more than offsets the negative effect of the increase in their relative supply.

The results are reported in Table 4. They show that the coefficient on the share of university graduates, although not as large as before is still well above zero. It is also interesting to note that the other coefficients such as those on communication and city size are very close to those obtained with the full sample.

\subsection{Spatial sorting}

The model above assumes that earnings differences between cities are explained only by exogenous differences in population and human capital. Furthermore, the disturbance terms in the earnings equation were assumed to be iid across cities, just like the social skills (i.e., the disturbance term in the communication equation). Instead, it could be that large cities 
attract workers with high le vels of human capital and social skills because of better amenities for instance. This alternative explanation based on sorting could easily explain the strong correlation between average human capital and earnings. This is a long-standing worry in the literature. As already noted by Alfred Marshall (1890 - p.199): "the large towns and especially London absorb the very best blood of all the rest of England; the most enterprising, the most highly gifted, those with the highest physique and strongest character go there to find scope for their abilities". Of course what applies to London could certainly apply to Paris.

To make a first cut at this issue, note that our data contains some information about the birthplace of workers. This information is at the level of the 95 French 'départements' which cover the country. This is certainly not ideal but we should be able to detect spatial sorting (if any) through different outcomes for those who work where they were born (the 'stayers') and the others (the 'movers'). We started by running our preferred earnings and communication equations with a full set of dummies. We gradually got rid of those that were not significant to reach the specifications that appear in Table 5. Column 1 reports the earnings equation with the relevant dummies for the movers. Interestingly we find that the returns to communication for movers are higher even after controlling for age, gender, education and city characteristics. We also find that movers benefit more from being in larger cities and in cities with more communication. Column 2 reports results for the communication equation. It shows that the effect of city size on communication is weaker for movers than for stayers .

These findings support the idea that workers sort themselves across cities. Workers with better unobserved abilities or social skills tend to go to larger cities and are able to benefit more from them. At the same time, these workers are less sensitive to their environment with respect to their communication behaviour. Hence, for movers only $7 \%$ of the effects of city size appear to percolate through communication externalities instead of $10 \%$ in the basic estimates. For stayers, about $25 \%$ of the effects of city size percolate through communication externalities.

An alternative approach is to treat worker location as a variable that is determined jointly with communication and wages. The argument behind this is that workers may decide whether to remain where they where born or to go to some other place with their choice being determined by the characteristics of the cities. This would then imply that city size and the share of graduates are determined simultaneously with wages and communication. The only possible instruments we have for the characteristics of the chosen location (share of graduates 
and population) are the occupational status of both parents at birth and the place of birth. In the first column of Table 6, we instrument the size of the city of residence and its share of graduates with the occupational status of the parents and the population density of the birthplace in 1990. Although not very conclusive, the results show that the coefficient on the share of graduates more than doubles whereas that on city population is divided by three and becomes insignificant. In the last column of Table 6 , the same procedure is applied to the communication equation. The coefficient on city size nearly doubles whereas that on the share of graduates remains very close to its baseline in Table 3 . Unfortunately both coefficients are insignificant. These disappointing results are caused by the weakness of our instruments. The $\mathrm{R}^{2}$ in the instrumental regressions are between 15 and $20 \%{ }^{25}$

In conclusion, we seem to have, on the one hand, good communicators who go to large cities and benefit strongly from them. These good communicators also have high returns to their own communication but they do not gain much from communication externalities. On the other hand, we have stayers with less favourable characteristics who are able to benefit relatively more from communication externalities. However, this evidence of spatial sorting does not modify greatly our previous conclusions. ${ }^{26}$ Communication externalities account for only a small share of the external effects of city size and average urban schooling.

\subsection{Endogeneity of communication}

Our communication variable has a lot of intuitive appeal but may be suspected of being simultaneously determined with the wage. Indeed, workers with higher (unobserved) abilities are likely to occupy positions implying both a higher wage and more communication. More generally, we may have ignored a crucial variable, which determines both earnings and communication. This estimation problem can again be investigated using instrumental variables. For good instruments, we need exogenous variables, which determine workplace communication, but remain un-correlated with the residual in our earnings equation.

\footnotetext{
${ }^{25}$ Note that this is not very surprising since idiosyncratic factors are known to play an important role in migration decisions.

${ }^{26}$ Even if sorting accounted for all our results, one would need to explain why 'good communicators' cluster in large cities where more communication takes place. If this is because they want to communicate more and these places offer opportunities (or a lower cost) to do so, the spirit of our results would not be modified. More serious would be the case of an omitted ability bias such that (i) it makes workers more efficient, (ii) it is correlated with large city location, and (iii) it leads workers to communicate more in a world where (iv) communication plays no productive role. However, it is unclear to us which plausible alternative model could satisfy these four conditions.
} 
In this respect, we can use the part of our data related to working conditions and changes in the work environment. Time spent daily in front of computer and having to do repetitive movements at work can be used as predictors for communication. Important recent changes in the work environment or in the organisation of work also predict the communication score of workers since such changes are typically correlated with a more important role for information technologies. These variables are not correlated with the residual in the earnings equation.

A Hausman specification test (Green, 2000) shows that indeed endogeneity is an issue here. However instrumenting communication by organisational change and working conditions does not change dramatically our results. Comparing the instrumental variables results reported in Table 6 Columns $2-4$ with those of Table 1, it appears first that the coefficient on individual communication doubles. In Columns 2 and 3, The coefficient on city population is now slightly higher at $2.2 \%$ whereas that of the share of graduates decreases from 0.5 to 0.3 . Overall, there is some simultaneity between communication and earnings. However, after instrumenting for communication, our results with respect to the importance of communication externalities remain roughly the same.

\subsection{Other issues}

Further to these considerations, one may assume that the provision of education is biased with high-wage cities offering more and better education. ${ }^{27}$ This channel could explain a positive correlation between earnings and average human capital. In France however, primary and secondary education is managed by the central government. The French education system is also very concerned about equity within the country. Consequently, the curriculum is the same everywhere. The central government also aims to equalize class size, resources spent per pupil, etc. Hence strong biases at the level of primary or secondary education are unlikely. The case of higher education is subtler. Paris hosts most of the best universities and 'grandes écoles'. ${ }^{28}$ The recruitment of most grandes écoles is national in scope so that any effect here should be part of the spatial sorting bias already explored. Universities have a local catchment area at the bachelor level. Parisian universities have a national recruitment at

\footnotetext{
${ }^{27}$ These issues are only given a cursory treatment here. They are dealt with at length by Moretti (2000) who shows that they only play a minor role. In his careful instrumentation of the share of graduates in the US, Moretti (2000) found that accounting for endogeneity here did not modify his conclusions, nor would the use of the longitudinal dimension of his data.
} 
the master and doctoral level. Hence, at the master and doctoral level, we are back again to spatial sorting. The unexplored bias regards university students in Paris, who during their first two or three years at university are able to study in more prestigious institutions like La Sorbonne. However, funding per student across universities is also equalised. Whether the more prestigious professors in Parisian universities are enough to create a large bias in the accumulation of human capital at the bachelor level is somewhat doubtful.

Finally, one may argue that city size is endogenous to wages. This again seems very unlikely. As shown by Eaton and Eckstein (1997), French cities have experienced parallel population growth over the last 200 years. Hence it is difficult to argue that causality runs from high wages to population growth. To corroborate this, Ciccone (2002) instruments the population of French départements in his analysis of agglomeration effects in Europe and finds only negligible endogeneity problems.

\section{Conclusions}

This paper addresses the issue of the external returns to human capital in cities. We focus on one particular channel through which human capital externalities are often alleged to percolate: communication externalities at the workplace. To estimate such externalities, we use a unique French data set, which surveys workplace communication for around 6000 workers in 1997. This allows us to estimate both a communication equation and an earnings equation using individual workplace communication as explanatory variable along with other personal and city characteristics.

We find that only around $10 \%$ of the effects of a larger and more educated city percolate through communication. Even acknowledging unobserved quality effects, it seems highly unlikely that communication externalities account for the bulk of the positive effects of larger and more educated cities on earnings. At the same time however, it is possible to interpret these findings in a more positive light and argue that communication externalities appear to be indeed present in cities.

These conclusions indicate three directions for future research. First, we are yet to explore the full richness of our data. These findings, based on an aggregate communication index, warrant further research into the details of the different media being used, the workers

$\overline{{ }^{28} \text { France has a two-tier system for higher education. 'Grandes écoles' (engineering, business and literature) }}$ 
involved, the type of communication taking place and how location matters with respect to these issues. Charlot and Duranton (2003) take some steps in this direction. The analysis of workplace communication could also be enriched by looking at firms rather than individual workers. Second, note that this paper makes some progress towards the identification of one channel through which human capital externalities are often argued to permeate. It also proposes a quantitative assessment of its importance taking into account the possible endogeneity of communication. We also took small steps to deal with the possible endogeneity of workers' location. Future work should be doing more on this aspect. Furthermore, the issues surrounding the endogeneity of firm location should also be dealt with in future work. Third, channels other than communication should be explored in more details. In particular and with respect to city size and average urban schooling, the benefits of labour market pooling and input-output linkages should receive more attention.

have competitive entrance examinations whereas there is no selection to enter university. 


\section{Appendix 1: Data Description}

\section{The enriched COI data}

The basic data is from the 1997 "Changement Organisationnel et Informatisation" (COI) survey. This data is composed of four different business surveys matched with one labour force survey. The first business survey (manufacturing) and the workforce survey for the associated workers were conducted by the French Ministry of Industry. The second (food industry) was conducted by the French Ministry of Agriculture while the last two surveys (DIY chains and accountants) were carried out by INSEE (French National Institute for Statistics and Economics Studies). The conception of the business survey in manufacturing, that of the labour survey, and the coordination of the 4 surveys were directed by Nathalie Greenan at the Centre d'Etudes de l'Emploi at the French Ministry of Labour.

This firm/employee matched survey is mostly concerned with organisational change and information technologies. This data was later on matched with the Déclaration Annuelle Des Salaires (DADS) and with Enquête Annuelle d'Entreprises (EAE) also from INSEE. The DADS data is collected for fiscal purpose. It is exhaustive on all French salaried workers and contains information about employment and earnings. Furthermore, for all workers born in October of even years (those selected for COI), it also contains a wealth of personal characteristics. The EAE survey is also exhaustive for all firms with more than 20 employees. It contains a wealth of firm level data.

Initially 4025 representative firms were selected from general manufacturing (2541), the Food industry (478), accounting firms (734), and DIY shops (272). Within each group (general manufacturing, food industry, accounting, DIY), firms were randomly drawn among those with 50 or more employees. This sectoral heterogeneity in the nature of the surveyed firms need not worry us because in most cases, the data is broken down by sector.

Interviewers went to interview directly 1, 2 or 3 randomly chosen employees in each selected firm. When it was impossible to meet face-to-face with an employee, the interviewers did the survey on the phone. A total of 8812 employees were initially drawn. In total, 6177 employee questionnaires were obtained from 3153 firms. The $30 \%$ of nonrespondents include employees who refused to respond (about 9\%), those who could not be found by the interviewers $(11 \%)$ and those who had left their firm by the end of the year $(9 \%)$ and could not subsequently be matched with the DADS data. Further details on the data 
can be found in Greenan and Mairesse (1999) and Greenan and Hamon-Cholet (2001a,b). The match with firm level data obtained from the business survey led to a loss of another 594 observations.

\section{Location data}

Using postcode data at the establishment level, this survey was matched to a set of spatial units. We lost another 101 observations in the process. Metropolitan France contains 361 urban areas where employment is at least 5,000. The rest of the country is classified into different levels of 'peri-urban' (i.e., remote suburban) and rural areas. For simplicity, outside urban areas we only distinguish suburban from rural areas.

Note that the French definition of urban areas in this typology is rather broad and matches rather closely that of (consolidated) metropolitan areas in the US except that the threshold is much below (5,000 jobs instead of 100,000 inhabitants). To be consistent with the breadth of the definition of urban areas, the definition of suburban area is rather restrictive and narrow. A 'suburban' area in this typology is usually a rather remote ring around an urban area (a.k.a. exurban or peri-urban). Unfortunately, because a significant fraction of these remote suburban areas are functionally linked with two or more cities, they cannot be matched to particular adjacent urban areas. Urban areas contain about $60 \%$ of the French population and $70 \%$ of French employment. Around $65 \%$ of our observations are located in urban areas. This slight urban under-representation is due to the over-representation of the food industry whose location is often rural. Suburban areas account for around $10 \%$ of our observations. Finally, $25 \%$ of the observations are located in rural areas.

\section{The communication questions}

The employee questionnaire contains around 80 questions covering a wide range of topics about working conditions, organisational change and information technologies. Regarding communication, the most relevant questions are:

30. Are you in contact (face-to-face or telephone) with customers? (All the time/Regularly/At times/ Never)

31. Except for your subordinates (if any), do you give instructions to the following persons 
about their work?

a/ Colleagues with whom you are usually working: Yes/No/Not Applicable.

b/ Others, working for the same firm: Y/N/NA.

c/ Others, working for another firm (customer, supplier, etc.): Y/N/NA.

32. Except for your superior(s), do you receive instructions from the following persons about your work?

a/ Colleagues with whom you are usually working: Y/N/NA.

b/ Others, working for the same firm: Y/N/NA.

c/ Others, working for another firm (customer, supplier, etc.): Y/N/NA.

34. How do you receive important instructions about your work?

a/ Face-to-face communication: Y/N.

b/ Telephone: Y/N.

c/ Paper (including fax, telex, etc.): Y/N.

d/ Computer (electronic mail, etc.): Y/N.

40. Do you do some of your work in a team? Y/N.

40b. If yes, are you involved with the following?

a/ Colleagues from the same unit: $\mathrm{Y} / \mathrm{N}$.

$\mathrm{b} /$ Others, from the same firm: Y/N .

c/ Others, external from your firm: Y/N .

40c. If yes, what type of work is concerned? Conception (or design, or research) /

Production

52. Do you use ever a PC or a workstation at work? Y/N.

55. Do you use information technologies to search for information? Y/N.

68. Do you use internet at work? Y/N.

69. Do you use an intranet at work? Y/N.

Note that these questions refer to different aspects of workplace communication. Question 30 
regards the intensity of external communication with customers. Unfortunately this is the only question in this direction. Questions 31,32, 40a and b refer to whom the worker communicate with. Note also that questions 31 and 32 relate to 'instructions' received or given by the worker. The questionnaire defines instructions as "important information received or given by the worker on a regular basis to conduct his or her work". Question 40c is of particular interest because it relates to creative activities upon which the literature puts special emphasis. The remaining questions refer to the media used by the worker for his or her workplace communication. The main weakness of this data is that we know where the surveyed workers are located but we do not know where the workers they communicate with are.

\section{Our communication indices}

The answers to all binary questions were coded 1 for yes and 0 for no. Answers to questions 30 were coded 4 for the highest level of communication, 3, 2, and 1 for the lowest. We then aggregated this into a varie ty of communication indices. Our main index, Com, is a weighted average. We gave an equal weight to the following five dimensions:

- Communication internal to the firm (sum of 31a, 31b, 32a, 32b, 40b a, and 40b-b).

- Communication external to the firm (sum of 31c, 32c, and 40b-c).

- Intensity of communication (30).

- Media (sum of 34a, b, c, d, e, 52, 55, 68, and 69).

- Involvement in creative activities with others (40c).

This index is normalised to be between 0 and 100. The mean score for our sample is 37.1 and the standard error is 21.3. We also constructed two alternative indices: Com_b and Com_c.Com_b is simply the sum of the score to all questions normalised to take a maximum of 100. Com_c is a slightly more complex index where external communication together with involvement in creative activities is given the same weight as internal communication. The sum of the two is then multiplied by the intensity of communication as measured by question 30. This product counts for $75 \%$. The remaining $25 \%$ are given by the sum to the media questions. Again this index is normalised to take a maximum of 100 .

We prefer Com because it gives more weights to the intensity of communication with persons external to the firm and the involvement in creative activities, which we view as potentially important channels for communication externalities. It is also consistent with the results of the principle component analysis that we conduct in Charlot and Duranton (2003). 
This analysis shows that the variables relating to external communication, the intensity of communication, and the use of IT and telecommunication have a strong spatial pattern. They enter heavily in the main axis which accounts for about a quarter of the variability. Two other axes account for about a tenth of the variability. They are about more routine forms of communication (e.g., face-to-face and internal communication) and team-work participation respectively. Our index reflects these features.

Concerning the possible alternatives to Com, Com_b is much simpler but internal communication may be over-represented because of the wealth of questions on this issue. Com_c is possibly more realistic since communication is weighted by its intensity but it relies to a large extent on the answer to only one question (30). The pair-wise correlation between these indices across workers is between 0.93 and 0.96 . We replicated all our regressions using Com with Com_b and Com_c. Unsurprisingly the results were never very different.

\section{Our average communication index}

The variable measuring average communication is the weighted mean city communication

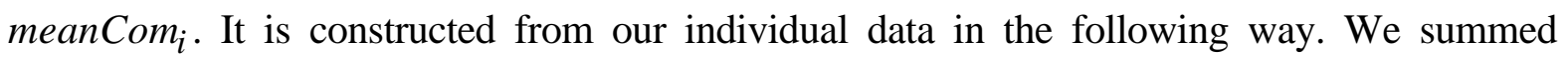
across educational attainments (denoted $g$ ), the product of the 1999-census share of shares of workers $\left(s_{i}(g)\right)$ by their empirical mean level of communication $\left(\operatorname{Com}_{i}(g)\right)$ :

$$
\operatorname{meanCom}_{i}=\sum_{g=1}^{6} s_{i}(g) \operatorname{Com}_{i}(g) \text {, }
$$

The problem is that in small cities, we have no observation for some educational attainments. To fill the blanks and using all the observations we have for the city, we computed the following communication ratio:

$$
q_{i}=\sum_{g=1}^{6}\left[\frac{n_{i}(g)}{n_{i}} \frac{\operatorname{Com}_{i}(g)}{\operatorname{Com}(g)}\right],
$$

where $n_{i}(g)$ is the number of workers in the sample with educational attainment $g$ in city $i$, $n_{i}$ is the sampled population in city $i$, and $\operatorname{Com}(g)$ is the national mean of workers of 
educational attainment $j$. We then proxied $\operatorname{Com}_{i}(g)$ by $q_{i} \operatorname{Com}(g)$.

Because we use the real proportion for each educational attainment, this index avoids sample selection biases for the composition of educational attainment for small urban areas for which we have no more than a handful of observations.

\section{Working condition variables}

To instrument for the possible endogeneity of workplace communication, we use data regarding working conditions:

- Computer use: number of hours spent daily in front of a computer.

(The information is coming from Question 79: On average how many hours do you spend in front of your computer if at all? Hours per week on average.)

- Repetitive movements: whether the position occupied by the worker involves the repetition of the same movement(s).

(Question 43. Does your work involve the continuous repetition of the same series of movements and/or operations? $\mathrm{Y} / \mathrm{N}$ )

- Organisational change: whether the working environment and the organisation of work has changed significantly in the last three years.

(Questions 8 and 8b. Has your working environment changed dramatically in the last three years? Y/N. If yes, is it because of a change of position? Y/N. A change of technique? Y/N. Restructuring of the firm? Y/N. A change in the organisation of your work? Y/N. Other?)

\section{Other variables}

The COI data contains 14 possible levels of educational attainment. Given the small population in some cells and the lack of discernible wage differences between some cells, we aggregated these 14 categories into the six, which are used by the French census.

Educ1: university graduates (a degree involving at least three years of higher education).

$E d u c 2$ : college graduates (two years of higher education).

Educ3: high-school graduates. 
Educ4: vocational school graduates.

Educ5: junior high-school graduates.

Educ6 (our reference): no degree (early school drop-out).

The variable shareGraduates was constructed from the 1999 census. It reports the share of the population in each area with our two highest levels of educational attainments (Educ1 or Educ2).

To distinguish retail (DIY) and accounting firms from manufacturing, we created two dummy variables:

Accounting for workers employed in accounting firms.

Retail for workers employed in DIY firms.

Workers in manufacturing are used as the reference.

The Wage variable refers to the net annualised earnings received by the employee. It comes from the DADS data. This data is collected from all employers (and self-employed) in France for pension, benefits and tax purposes. A report must be filled by every establishment for each of its employees so that there is a unique record for each employee-establishment-year combination. The mandatory aspect of this data is a guarantee of its quality.

The occupational dummy Non-routine was created from the detailed information in the COI data about the occupation. We classified as non-routine' all jobs that a priori involve some autonomy for the employee. All other occupations were classified as 'routine'. Among non-routine jobs, we have functions such as: sales, management, accounting, research, teaching, etc whereas we classified as routines functions like cleaning, production, domestic work, handling of goods, etc. This distinction attempts to generalise the usual white collar / blue collar opposition in manufacturing. We tried more detailed breakdowns for the occupations. This only led to minor changes in our results.

We exploited the information about the place of birth (at the level of the 95 French départements --- these units are comparable to counties in the US or the UK) and the place of work. If someone works in the département he or she was born, this person is classified as a stayer. Otherwise, this person is a mover. In our sample, we have $43 \%$ of movers and $57 \%$ of stayers. We also used data from the 1990 census to compute population density in the place of birth in 1990.

Finally the occupational status of the father and mother at birth is also coming from 
the COI data. Occupations are classified according to the one-digit French classification of occupations, which contains eight entries (inactive/student, unskilled blue-collar, skilled bluecollar, white-collar employee, self-employed, intermediate profession, professional, apprentice). 


\section{Appendix 2: Results}

\section{Table 1: Earnings equations}

$\log \mathrm{W}$

\begin{tabular}{|c|c|c|c|c|c|c|}
\hline Regressors & (1) & (2) & (3) & (4) & (5) & (6) \\
\hline \multirow[t]{2}{*}{ Intercept } & 1.618 & 1.600 & 1.670 & 1.767 & 1.936 & 1.911 \\
\hline & $(0.0956)$ & $(0.0957)$ & $(0.0892)$ & $(0.0903)$ & $(0.0826)$ & $(0.0856)$ \\
\hline \multirow[t]{2}{*}{ Gender } & -0.209 & -0.207 & -0.209 & -0.210 & -0.1978 & -0.217 \\
\hline & $(0.00932)$ & $(0.00932)$ & $(0.00932)$ & $(0.00932)$ & $(0.00934)$ & $(0.00962)$ \\
\hline \multirow[t]{2}{*}{ Educ1 } & 0.573 & 0.578 & 0.570 & 0.576 & 0.624 & 0.827 \\
\hline & $(0.0218)$ & $(0.0218)$ & $(0.0217)$ & $(0.0218)$ & $(0.0212)$ & $(0.0193)$ \\
\hline \multirow[t]{2}{*}{ Educ2 } & 0.332 & 0.331 & 0.329 & 0.336 & 0.351 & 0.513 \\
\hline & $(0.0197)$ & (0.0198) & (0.0197) & $(0.0198)$ & $(0.0197)$ & $(0.0186)$ \\
\hline \multirow[t]{2}{*}{ Educ3 } & 0.211 & 0.210 & 0.209 & 0.214 & 0.221 & 0.346 \\
\hline & $(0.0188)$ & (0.0189) & $(0.0188)$ & $(0.0188)$ & $(0.0189)$ & $(0.0185)$ \\
\hline \multirow[t]{2}{*}{ Educ4 } & 0.109 & 0.107 & 0.107 & 0.109 & 0.109 & 0.176 \\
\hline & $(0.0145)$ & $(0.0145)$ & $(0.0144)$ & $(0.0145)$ & $(0.0146)$ & $(0.0147)$ \\
\hline \multirow[t]{2}{*}{ Educ5 } & $0.0217^{\mathrm{ns}}$ & $0.0194^{\mathrm{ns}}$ & $0.0204^{\mathrm{ns}}$ & $0.0223^{\mathrm{ns}}$ & $0.0175^{\mathrm{ns}}$ & 0.0434 \\
\hline & $(0.0185)$ & $(0.0185)$ & $(0.0185)$ & $(0.0185)$ & $(0.0187)$ & $(0.0194)$ \\
\hline \multirow[t]{2}{*}{ Age } & 0.0705 & 0.0702 & 0.0704 & 0.0706 & 0.0701 & 0.0759 \\
\hline & $(0.00406)$ & $(0.00407)$ & $(0.00406)$ & $(0.00407)$ & $(0.00408)$ & $(0.00422)$ \\
\hline \multirow[t]{2}{*}{ Age $^{2}$} & -0.000616 & -0.000612 & -0.000614 & -0.000616 & -0.000600 & -0.000660 \\
\hline & $(0.0000491)$ & $(0.0000492)$ & $(0.0000491)$ & $(0.0000492)$ & $(0.0000492)$ & $(0.0000560)$ \\
\hline \multirow[t]{2}{*}{ Com } & 0.00458 & 0.00466 & 0.00467 & 0.00461 & 0.00507 & \\
\hline & $(0.000261)$ & $(0.000261)$ & $(0.000254)$ & $(0.000261)$ & $(0.000253)$ & \\
\hline \multirow[t]{2}{*}{ Rural } & 0.205 & 0.305 & 0.208 & & & \\
\hline & $(0.0402)$ & $(0.0338)$ & $(0.0401)$ & & & \\
\hline \multirow[t]{2}{*}{ Suburb } & 0.224 & 0.345 & 0.227 & & & \\
\hline & $(0.0443)$ & $(0.0355)$ & $(0.0442)$ & & & \\
\hline \multirow[t]{2}{*}{$\operatorname{logPop}$} & 0.0192 & 0.0297 & 0.0195 & & & \\
\hline & $(0.00349)$ & $(0.00263)$ & $(0.00348)$ & & & \\
\hline \multirow[t]{2}{*}{ meanCom } & $0.00116{ }^{c}$ & $0.000581^{\text {ns }}$ & & $0.00142^{b}$ & & \\
\hline & $(0.000771)$ & $(0.000762)$ & & $(0.000771)$ & & \\
\hline \multirow[t]{2}{*}{ shareGraduates } & 0.490 & & 0.463 & 0.891 & & \\
\hline & $(0.107)$ & & $(0.105)$ & $(0.0740)$ & & \\
\hline Adj. $\mathrm{R}^{2}$ & 0.489 & 0.487 & 0.489 & 0.486 & 0.483 & 0.446 \\
\hline N. obs & 5329 & 5329 & 5329 & 5329 & 5329 & 5329 \\
\hline
\end{tabular}

Note: Standard errors are shown in parentheses. All coefficient significant at the $1 \%$ level except ${ }^{\text {a }}$ significantly different from zero at the $5 \%$ level, ${ }^{\mathrm{b}}$ significantly different from zero at the $10 \%$ level and ${ }^{\mathrm{c}}$ significantly different from zero at the $15 \%$ level, ${ }^{\text {ns }}$ not significant. 
Table 2: Augmented earnings equations

\begin{tabular}{|c|c|c|c|c|}
\hline Regressors & (1) & (2) & (3) & (4) \\
\hline \multirow[t]{2}{*}{ Intercept } & 1.750 & 1.776 & 1.726 & 1.747 \\
\hline & $(0.119)$ & $(0.0984)$ & (0.0990) & (0.0993) \\
\hline \multirow[t]{2}{*}{ Gender } & $-0.274^{\mathrm{c}}$ & -0.225 & -0.229 & -0.197 \\
\hline & $(0.172)$ & $(0.00997)$ & $(0.00992)$ & $(0.00972)$ \\
\hline \multirow[t]{2}{*}{ Educ1 } & 0.502 & 0.505 & 0.541 & 0.559 \\
\hline & $(0.0222)$ & $(0.0222)$ & $(0.0223)$ & (0.0219) \\
\hline \multirow[t]{2}{*}{ Educ2 } & 0.259 & 0.262 & 0.301 & 0.320 \\
\hline & $(0.0203)$ & $(0.0203)$ & (0.0204) & (0.0198) \\
\hline \multirow[t]{2}{*}{ Educ3 } & 0.163 & 0.165 & 0.183 & 0.212 \\
\hline & $(0.0192)$ & $(0.0192)$ & (0.0194) & $(0.0188)$ \\
\hline \multirow[t]{2}{*}{ Educ4 } & 0.0887 & 0.0890 & 0.0972 & 0.111 \\
\hline & $(0.0143)$ & $(0.0143)$ & $(0.0146)$ & $(0.0143)$ \\
\hline \multirow[t]{2}{*}{ Educ5 } & $0.0202^{\mathrm{ns}}$ & $0.0194^{\mathrm{ns}}$ & $0.0251^{\mathrm{ns}}$ & $0.0210^{\mathrm{ns}}$ \\
\hline & $(0.0181)$ & $(0.0181)$ & $(0.0184)$ & $(0.0183)$ \\
\hline \multirow[t]{2}{*}{ Age } & 0.0614 & 0.0615 & 0.0656 & 0.0624 \\
\hline & $(0.00547)$ & $(0.00431)$ & $(0.00437)$ & $(0.00435)$ \\
\hline \multirow[t]{2}{*}{$\mathrm{Age}^{2}$} & -0.000508 & -0.000524 & -0.000563 & -0.000525 \\
\hline & $(0.0000652)$ & $(0.0000519)$ & $(0.0000526)$ & $(0.0000524)$ \\
\hline \multirow[t]{2}{*}{ Children } & 0.0170 & $0.0129^{a}$ & 0.0128 & 0.0116 \\
\hline & $(0.00486)$ & $(0.00408)$ & $(0.00415)$ & $(0.00412)$ \\
\hline \multirow[t]{2}{*}{ Gender X Age } & $0.000775^{\mathrm{ns}}$ & & & \\
\hline & $(0.00889)$ & & & \\
\hline \multirow[t]{2}{*}{ Gender X Age ${ }^{2}$} & $-0.0000141^{\mathrm{ns}}$ & & & \\
\hline & $(0.000108)$ & & & \\
\hline \multirow[t]{2}{*}{ Gender X Children } & $-0.0194^{\mathrm{a}}$ & & & \\
\hline & $(0.00895)$ & & & \\
\hline \multirow[t]{2}{*}{ Non-routine occup. } & 0.135 & 0.138 & 0.0794 & \\
\hline & $(0.0131)$ & $(0.0131)$ & $(0.0123)$ & \\
\hline \multirow[t]{2}{*}{ Accounting } & 0.0959 & 0.0952 & & 0.0470 \\
\hline & $(0.0140)$ & $(0.0139)$ & & $(0.0133)$ \\
\hline \multirow[t]{2}{*}{ Retail } & -0.160 & -0.160 & & -0.156 \\
\hline & $(0.0217)$ & $(0.0217)$ & & $(0.0219)$ \\
\hline \multirow[t]{2}{*}{ Com } & 0.00392 & 0.00392 & 0.00386 & 0.00502 \\
\hline & $(0.000279)$ & $(0.000279)$ & $(0.000284)$ & $(0.000262)$ \\
\hline \multirow[t]{2}{*}{ Rural } & $\overline{0.14 \overline{5}}$ & 0.150 & 0.206 & 0.164 \\
\hline & $(0.0396)$ & $(0.0396)$ & $(0.0400)$ & $(0.0400)$ \\
\hline \multirow[t]{2}{*}{ Suburb } & 0.165 & 0.168 & 0.223 & 0.184 \\
\hline & $(0.0436)$ & $(0.0437)$ & $(0.0441)$ & $(0.0441)$ \\
\hline \multirow[t]{2}{*}{$\log P o p$} & 0.0149 & 0.0153 & 0.0187 & 0.0168 \\
\hline & $(0.00342)$ & $(0.00342)$ & $(0.00347)$ & $(0.00346)$ \\
\hline \multirow[t]{2}{*}{ meanCom } & $0.00161^{a}$ & $0.00162^{\mathrm{a}}$ & $0.00123^{b}$ & $0.00147^{b}$ \\
\hline & $(0.000754)$ & $(0.000755)$ & $(0.000767)$ & $(0.000763)$ \\
\hline \multirow[t]{2}{*}{ shareGraduates } & 0.496 & 0.480 & 0.468 & 0.514 \\
\hline & $(0.104)$ & $(0.104)$ & $(0.106)$ & $(0.105)$ \\
\hline Adj. $R^{2}$ & 0.512 & 0.510 & 0.493 & 0.500 \\
\hline N. obs & 5329 & 5329 & 5329 & 5329 \\
\hline
\end{tabular}

Note: Standard errors are shown in parentheses. All coefficient significant at the $1 \%$ level except ${ }^{\text {a }}$ significantly different from zero at the $5 \%$ level, ${ }^{\mathrm{b}}$ significantly different from zero at the $10 \%$ level and ${ }^{\mathrm{c}}$ significantly different from zero at the $15 \%$ level, ${ }^{\text {ns }}$ non significant. 
Table 3: Communication equations

Com

\begin{tabular}{|c|c|c|c|c|}
\hline Regressors & (1) & (2) & (3) & (4) \\
\hline \multirow[t]{2}{*}{ Intercept } & $-8.814^{b}$ & -39.611 & $-8.677^{b}$ & $-3.453^{\mathrm{ns}}$ \\
\hline & $(4.819)$ & $(4.990)$ & $(4.741)$ & $(4.396)$ \\
\hline \multirow[t]{2}{*}{ Gender } & -3.998 & -3.855 & -5.129 & -8.118 \\
\hline & $(0.501)$ & $(0.487)$ & $(0.510)$ & $(0.483)$ \\
\hline \multirow[t]{2}{*}{ Educ1 } & 37.834 & 37.480 & 36.934 & 24.363 \\
\hline & $(1.052)$ & (1.022) & $(1.025)$ & $(1.037)$ \\
\hline \multirow[t]{2}{*}{ Educ2 } & 30.781 & 30.780 & 30.143 & 18.100 \\
\hline & $(0.975)$ & $(0.947)$ & $(0.963)$ & $(0.978)$ \\
\hline \multirow[t]{2}{*}{ Educ3 } & 23.819 & 23.652 & 22.433 & 12.968 \\
\hline & $(0.962)$ & $(0.935)$ & $(0.956)$ & $(0.940)$ \\
\hline \multirow[t]{2}{*}{ Educ4 } & 12.828 & 13.002 & 12.310 & 7.575 \\
\hline & $(0.760)$ & $(0.738)$ & $(0.748)$ & $(0.711)$ \\
\hline \multirow[t]{2}{*}{ Educ5 } & 4.933 & 5.437 & 5.330 & 4.178 \\
\hline & $(0.997)$ & $(0.969)$ & $(0.977)$ & $(0.906)$ \\
\hline \multirow[t]{2}{*}{ Age } & 1.114 & 1.133 & 1.258 & 1.019 \\
\hline & $(0.219)$ & $(0.213)$ & $(0.214)$ & $(0.198)$ \\
\hline \multirow[t]{2}{*}{$\mathrm{Age}^{2}$} & -0.0120 & -0.0120 & -0.0131 & -0.012 \\
\hline & $(0.00265)$ & $(0.00257)$ & $(0.00258)$ & $(0.00239)$ \\
\hline \multirow[t]{2}{*}{ Non-routine occup. } & & & & 18.115 \\
\hline & & & & $(0.603)$ \\
\hline \multirow[t]{2}{*}{ Accounting } & & & -6.053 & $0.982^{\mathrm{ns}}$ \\
\hline & & & $(0.696)$ & $(0.686)$ \\
\hline \multirow[t]{2}{*}{ Retail } & & & 4.790 & 3.397 \\
\hline & & & $(1.173)$ & $(1.088)$ \\
\hline \multirow[t]{2}{*}{ Rural } & $1.393^{\mathrm{ns}}$ & $-0.314^{\mathrm{ns}}$ & $4.261^{\mathrm{a}}$ & $1.776^{\mathrm{ns}}$ \\
\hline & $(2.170)$ & $(2.110)$ & (2.037) & $(1.889)$ \\
\hline \multirow[t]{2}{*}{ Suburb } & $3.578^{c}$ & $1.156^{\mathrm{ns}}$ & 6.297 & $3.381^{c}$ \\
\hline & (2.391) & $(2.327)$ & (2.244) & $(2.081)$ \\
\hline \multirow[t]{2}{*}{$\operatorname{logPop}$} & $0.385^{a}$ & $0.178^{\text {ns }}$ & 0.528 & $0.253^{c}$ \\
\hline & $(0.188)$ & $(0.183)$ & $(0.173)$ & $(0.161)$ \\
\hline \multirow[t]{2}{*}{ meanCom } & & 0.701 & & \\
\hline & & $(0.0393)$ & & \\
\hline \multirow[t]{2}{*}{ shareGraduates } & $13.092^{a}$ & 28.238 & $11.458^{a}$ & $5.232 \mathrm{~ns}$ \\
\hline & $(5.687)$ & $(5.590)$ & $(5.410)$ & $(5.016)$ \\
\hline Adj. $R^{2}$ & 0.318 & 0.357 & 0.345 & 0.438 \\
\hline N. obs & 5329 & 5329 & 5482 & 5482 \\
\hline
\end{tabular}

Note: Standard errors are shown in parentheses. All coefficient significant at the $1 \%$ level except ${ }^{\text {a }}$ significantly different from zero at the $5 \%$ level, ${ }^{b}$ significantly different from zero at the $10 \%$ level and ${ }^{\mathrm{c}}$ significantly different from zero at the $15 \%$ level, ${ }^{\mathrm{ns}}$ non significant. 
Table 4: Earnings equations for university educated workers only

\begin{tabular}{|c|c|c|}
\hline Regressors & (1) & (2) \\
\hline \multirow[t]{2}{*}{ Intercept } & 1.343 & 1.268 \\
\hline & $(0.191)$ & $(0.200)$ \\
\hline \multirow[t]{2}{*}{ Gender } & -0.190 & -0.209 \\
\hline & $(0.0213)$ & $(0.0222)$ \\
\hline \multirow[t]{2}{*}{ Educ1 } & 0.229 & \\
\hline & $(0.0209)$ & \\
\hline \multirow[t]{2}{*}{ Age } & 0.0953 & 0.0967 \\
\hline & $(0.00914)$ & $(0.00957)$ \\
\hline \multirow[t]{2}{*}{$\mathrm{Age}^{2}$} & -0.000788 & -0.000786 \\
\hline & $(0.000113)$ & $(0.000118)$ \\
\hline \multirow[t]{2}{*}{ Com } & 0.00411 & 0.00519 \\
\hline & $(0.000523)$ & $(0.000538)$ \\
\hline \multirow[t]{2}{*}{ Rural } & 0.276 & 0.308 \\
\hline & $(0.0776)$ & $(0.0811)$ \\
\hline \multirow[t]{2}{*}{ Suburb } & 0.245 & 0.272 \\
\hline & $(0.0852)$ & $(0.0891)$ \\
\hline \multirow[t]{2}{*}{$\log$ Pop } & 0.0236 & 0.0273 \\
\hline & $(0.00595)$ & $(0.00622)$ \\
\hline \multirow[t]{2}{*}{ shareGraduates } & $0.350^{b}$ & $0.413^{a}$ \\
\hline & $(0.196)$ & $(0.205)$ \\
\hline Adj. $\mathrm{R}^{2}$ & 0.576 & 0.538 \\
\hline N. obs & 1256 & 1256 \\
\hline
\end{tabular}

Note: Standard errors are shown in parentheses. All coefficient significant at the $1 \%$ level except ${ }^{\text {a }}$ significantly different from zero at the $5 \%$ level, ${ }^{\mathrm{b}}$ significantly different from zero at the $10 \%$ level and ${ }^{\mathrm{c}}$ significantly different from zero at the $15 \%$ level, ${ }^{\mathrm{ns}}$ not significant. 
Table 5: Earnings and communication equations with controls for movers and stayers

\begin{tabular}{|c|c|c|c|}
\hline \multicolumn{2}{|l|}{$\log \mathrm{W}$} & \multicolumn{2}{|l|}{ Com } \\
\hline Regressors & (1) & Regressors & (2) \\
\hline \multirow[t]{2}{*}{ Intercept } & 1.822 & Intercept & $-7.520^{\mathrm{c}}$ \\
\hline & (0.109) & & $(4.808)$ \\
\hline \multirow[t]{2}{*}{ Mover } & -0.345 & Stayer & -2.708 \\
\hline & $(0.100)$ & & $(0.831)$ \\
\hline \multirow[t]{2}{*}{ Gender } & -0.209 & Gender & -3.943 \\
\hline & $(0.00930)$ & & $(0.494)$ \\
\hline \multirow[t]{2}{*}{ Educ1 } & 0.560 & Educ1 & 37.886 \\
\hline & (0.0219) & & (1.018) \\
\hline \multirow[t]{2}{*}{ Educ2 } & 0.329 & Educ2 & 30.696 \\
\hline & (0.0197) & & (0.964) \\
\hline \multirow[t]{2}{*}{ Educ3 } & 0.209 & Educ3 & 23.713 \\
\hline & (0.0188) & & $(0.955)$ \\
\hline \multirow[t]{2}{*}{ Educ4 } & 0.108 & Educ4 & 12.988 \\
\hline & $(0.0144)$ & & $(0.757)$ \\
\hline \multirow[t]{2}{*}{ Educ5 } & $0.0209^{\mathrm{ns}}$ & Educ5 & 5.323 \\
\hline & $(0.0185)$ & & (0.992) \\
\hline \multirow[t]{2}{*}{ Age } & 0.0703 & Age & 1.113 \\
\hline & $(0.00406)$ & & $(0.216)$ \\
\hline \multirow[t]{2}{*}{$\mathrm{Age}^{2}$} & -0.000615 & $\mathrm{Age}^{2}$ & -0.0117 \\
\hline & $(0.0000490)$ & & $(0.00261)$ \\
\hline \multirow[t]{2}{*}{ Com } & 0.00392 & & \\
\hline & (0.000333) & & \\
\hline \multirow[t]{2}{*}{ Mover X Com } & 0.00138 & & \\
\hline & $(0.000442)$ & & \\
\hline \multirow[t]{2}{*}{ Rural } & $0.0677^{\mathrm{ns}-}$ & Rural & $2.103^{-\mathrm{ns}^{--}}$ \\
\hline & $(0.0602)$ & & $(2.140)$ \\
\hline \multirow[t]{2}{*}{ Suburb } & $0.0998^{\mathrm{c}}$ & Suburb & $4.078^{\mathrm{b}}$ \\
\hline & $(0.0635)$ & & (2.329) \\
\hline \multirow[t]{2}{*}{ Mover X Rural } & 0.206 & & \\
\hline & $(0.0741)$ & & \\
\hline \multirow[t]{2}{*}{ Mover X Suburb } & $0.171^{\mathrm{a}}$ & & \\
\hline & $(0.0771)$ & & \\
\hline \multirow[t]{2}{*}{$\operatorname{logPop}$} & $0.00822^{c}$ & $\operatorname{logPop}$ & $0.325^{b}$ \\
\hline & $(0.00520)$ & & $(0.177)$ \\
\hline \multirow[t]{2}{*}{ Mover X $\log P o p$} & 0.0151 & Stayer X logPop & $0.197^{\mathrm{a}}$ \\
\hline & $(0.00586)$ & & $(0.0825)$ \\
\hline \multirow[t]{2}{*}{ shareGraduates } & 0.449 & shareGraduates & $11.946^{\mathrm{a}}$ \\
\hline & $(0.107)$ & & (5.536) \\
\hline \multirow[t]{2}{*}{ meanCom } & $0.0000630^{\text {ns }}$ & & \\
\hline & $(0.000968)$ & & \\
\hline \multirow[t]{2}{*}{ Mover X meanCom } & 0.00307 & & \\
\hline & $(0.00156)$ & & \\
\hline Adj. $R^{2}$ & 0.492 & Adj. $R^{2}$ & 0.326 \\
\hline N. obs & 5329 & N. obs & 5482 \\
\hline
\end{tabular}

Note: Standard errors are shown in parentheses. All coefficient significant at the $1 \%$ level except ${ }^{\text {a }}$ significantly different from zero at the $5 \%$ level, ${ }^{\mathrm{b}}$ significantly different from zero at the $10 \%$ level and ${ }^{\mathrm{c}}$ significantly different from zero at the $15 \%$ level, ${ }^{\text {ns }}$ not significant. 
Table 6: IV estimations

\begin{tabular}{|c|c|c|c|c|c|}
\hline & $\log W$ & $\log W$ & $\log W$ & $\log W$ & Com \\
\hline Regressors & (IV1) & (IV2) & (IV3) & (IV4) & (IV5) \\
\hline \multirow[t]{2}{*}{ Intercept } & 1.790 & 1.673 & 1.674 & 1.833 & $-4.583^{\mathrm{ns}}$ \\
\hline & $(0.128)$ & $(0.0965)$ & $(0.0966)$ & $(0.125)$ & (7.162) \\
\hline \multirow[t]{2}{*}{ Gender } & -0.222 & -0.190 & -0.190 & -0.199 & -4.566 \\
\hline & $(0.0106)$ & $(0.0103)$ & $(0.0103)$ & $(0.0118)$ & $(0.578)$ \\
\hline \multirow[t]{2}{*}{ Educ1 } & 0.548 & 0.388 & 0.386 & 0.382 & 33.212 \\
\hline & $(0.0262)$ & $(0.0334)$ & $(0.0333)$ & $(0.0335)$ & (1.517) \\
\hline \multirow[t]{2}{*}{ Educ2 } & 0.307 & 0.176 & 0.174 & 0.173 & 26.630 \\
\hline & $(0.0243)$ & $(0.0286)$ & $(0.0285)$ & $(0.0285)$ & (1.415) \\
\hline \multirow[t]{2}{*}{ Educ3 } & 0.185 & 0.0879 & 0.0869 & 0.0825 & 20.232 \\
\hline & $(0.0256)$ & $(0.0254)$ & $(0.0253)$ & $(0.0263)$ & (1.493) \\
\hline \multirow[t]{2}{*}{ Educ4 } & 0.0886 & $0.0378^{a}$ & $0.0371^{\mathrm{a}}$ & $0.0349^{b}$ & 10.526 \\
\hline & $(0.0174)$ & $(0.0180)$ & $(0.0180)$ & $(0.0182)$ & (0.989) \\
\hline \multirow[t]{2}{*}{ Educ5 } & $0.0224^{\mathrm{ns}}$ & $-0.000351^{\mathrm{ns}}$ & $-0.000585^{\mathrm{ns}}$ & $0.00317^{\mathrm{ns}}$ & 3.796 \\
\hline & $(0.0209)$ & $(0.0210)$ & $(0.0210)$ & $(0.0213)$ & (1.170) \\
\hline \multirow[t]{2}{*}{ Age } & 0.0696 & 0.0643 & 0.0642 & 0.0645 & 0.991 \\
\hline & $(0.00473)$ & $(0.00456)$ & $(0.00446)$ & $(0.00472)$ & $(0.266)$ \\
\hline \multirow[t]{2}{*}{$\mathrm{Age}^{2}$} & -0.000604 & -0.000546 & -0.000545 & -0.00055 & -0.0103 \\
\hline & $(0.0000571)$ & $(0.0000543)$ & $(0.0000547)$ & $(0.0000572)$ & $(0.00318)$ \\
\hline \multirow[t]{2}{*}{ Com } & 0.00402 & 0.00977 & 0.00982 & 0.00899 & \\
\hline & $(0.000303)$ & $(0.000696)$ & $(0.000692)$ & $(0.000878)$ & \\
\hline \multirow[t]{2}{*}{ Rural } & -0.0505 & 0.238 & 0.238 & -0.0528 & -3.725 \\
\hline & $(0.0114)$ & $(0.0417)$ & $(0.0417)$ & $(0.0117)$ & $(0.636)$ \\
\hline \multirow[t]{2}{*}{ Suburb } & $-0.0141^{\mathrm{ns}}$ & 0.277 & 0.277 & $-0.00693^{\mathrm{ns}}$ & $-1.664^{b}$ \\
\hline & $(0.0160)$ & $(0.0458)$ & $(0.0458)$ & $(0.0164)$ & $(0.893)$ \\
\hline \multirow[t]{2}{*}{$\operatorname{logPop}$} & 0.00630 ns & 0.0220 & 0.0220 & $0.00219^{\text {ns }}$ & $0.797^{\text {ns }}$ \\
\hline & $(0.0105)$ & $(0.00358)$ & $(0.00358)$ & $(0.0102)$ & $(0.580)$ \\
\hline \multirow[t]{2}{*}{ shareGraduates } & $1.350^{b}$ & 0.322 & 0.322 & $1.241^{b}$ & $14.946^{\mathrm{ns}}$ \\
\hline & $(0.800)$ & $(0.112)$ & $(0.112)$ & $(0.741)$ & $(44.761)$ \\
\hline Adj. $\mathrm{R}^{2}$ & 0.495 & 0.486 & 0.486 & 0.480 & 0.299 \\
\hline N. obs & 4888 & 4888 & 4888 & 4888 & 4888 \\
\hline
\end{tabular}

Note: Standard errors are shown in parentheses. All coefficients significant at the $1 \%$ level except ${ }^{\text {a }}$ significantly different from zero at the $5 \%$ level, ${ }^{\mathrm{b}}$ significantly different from zero at the $10 \%$ level and ${ }^{\mathrm{c}}$ significantly different from zero at the $15 \%$ level, ${ }^{\mathrm{ns}}$ not significant. There are fewer observations than in previous tables because the density of the birthplace is not available for workers born abroad.

In Column $1, \log$ city population ( $\log P o p$ ) and the share of university graduates ( shareGraduates) are instrumented by the one digit occupational category of the father at birth, the same variable for the mother and the log of density in 1990 for the place of birth (at the level 95 French departments). (The $\mathrm{R}^{2}$ of the first instrumental regression- $\log P o p-$ is rather low at $14 \%$. That of the second instrumental regression - shareGraduates - is also low at $19 \%$.)

In Column 2, communication is instrumented by Computer use (see Appendix 1) and Repetitive movements. These variables are significant at $1 \%$ in the instrumental regression and are not correlated with the error term of the augmented regression.

In Column 3, communication is instrumented by the same variables plus Organisational change. The $\mathrm{R}^{2}$ of the instrumental regression is at $41 \%$.

In Column 4, we instrument communication, $\log$ population and the share of graduates by the instruments above.

In Column 5, we do as in column 1 using communication instead of wages as dependent variable. 


\section{References}

Abdel-Rahman, H. M. (1988), 'Product Differentiation, Monopolistic Competition and City Size', Regional Science and Urban Economics, 18, pp. 69-86.

Acemoglu, D. and Angrist, J. (2000), 'How Large Are Human Capital Externalities?

Evidence from Compulsory Schooling Laws', NBER Macroeconomics Annual, 15, pp. 9-59.

Adserà, A. (2000), 'Sectoral Spillovers and the Price of Land: A Cost Analysis across U.S. States', Regional Science and Urban Economics, 30, pp. 565-585.

Almeida, P. and Kogut, B. (1999), 'Localization of Knowledge and the Mobility of Engineers in Regional Networks’, Management Science, 45, pp. 905-917.

Beckmann, M. J. (1976), 'Spatial Equilibrium in the Dispersed City', in Y. Y. Papageorgiou (ed.), Mathematical Land Use Theory, Lexington Books, Lexington (Mass.), pp.117125.

Berliant, M., Reed, J. and Wang, P. (2001), 'Knowledge Exchange, Matching and Agglomeration', processed, University of Washington, St Louis.

Black, D. and Henderson, V. (1999), 'A Theory of Urban Growth', Journal of Political Economy, 107, pp. 252-284.

Borukhov, E. and Hochman, O. (1977), 'Optimum and the Market in a Model of City Without a Predetermined Center', Environment and Planning, A 9, pp. 849-856.

Brock, W. A. and Durlauf, S. N. (2001), 'Interactions-Based Model', in J. J. Heckman and E. Leamer (eds), Handbook of Econometrics, vol 5, North-Holland, Amsterdam, pp. 3297-3380.

Charlot, S. and Duranton, G. (2003), 'Cities and Workplace Communication: Some French Evidence', mimeo in progress.

Ciccone, A. (2002), 'Agglomeration Effects in Europe', European Economic Review, 46, pp. 213-227.

Ciccone, A. and Peri, G. (2002), 'Identifying Human Capital and Externalities: Theory with an Application to US Cities', CEPR discussion paper 3350.

Cohen, D. and Soto, M. (2001), 'Growth and Education: Good Data, Good Results', CEPR discussion paper 3025 .

Dixit, A. K. and Stiglitz, J. E. (1977), 'Monopolistic Competition and Optimum Product Diversity', American Economic Review, 67, pp. 297-308.

Dumais, G., Ellison, G. and Glaeser, E. (1997), 'Geographic Concentration as a Dynamic Process', NBER Working Paper 6270. 
Duranton, G. and Puga, D. (2003), 'Microeconomic Foundations of Urban Increasing Returns', in J. V. Henderson and J. F. Thisse (eds), Handbook of Regional and Urban Economics, vol 4, North-Holland, Amsterdam, forthcoming.

Eaton, J. and Eckstein, Z. (1997), 'Cities and Growth: Theory and Evidence from France and Japan', Regional Science and Urban Economics, 27, pp. 443-474.

Ethier, W. J. (1982), 'National and International Returns to Scale in the Modern Theory of International Trade', American Economic Review, 72, pp. 389-405.

Fujita, M. (1988), 'A Monopolistic Competition Model of Spatial Agglomeration: A Differentiated Product Approach', Regional Science and Urban Economics, 18, pp. 87-124.

Fujita, M. and Ogawa, H. (1982), 'Multiple Equilibria and Structural Transition of Nonmonocentric Urban Configurations', Regional Science and Urban Economics, 12, pp. 161-196.

Gaspar, J. and Glaeser, E. L. (1998), 'Information Technologies and the Future of Cities', Journal of Urban Economics, 43, pp. 136-156.

Glaeser, E. L. (1999), 'Learning in Cities', Journal of Urban Economics, 46, pp. 254-277.

Glaeser, E. L. and Maré, D. (2001), 'Cities and Skills', Journal of Labor Economics, 19, pp. 316-342.

Goddard, J. B. (1973), 'Office Linkages and Location: A Study of Communications and Spatial Patterns in Central London', Progress in Planning, 1, pp. 111-232.

Goddard, J. B. and Morris, D. (1976), 'The Communication Factors in Office Decentralisation', Progress in Planning, 6, pp. 1-80.

Greene, W. H. (2000), Econometric Analysis, Prentice Hall International, London.

Greenan, N. and Hamon-Cholet, S. (2001a), 'COI un Dispositif d'Enquêtes Couplées Employeurs / Employés sur les Changements Organisationnels et l'Informatisation. Tome 1 : Présentation et Questionnaires', processed Centre d'Etude de l'Emploi, Paris.

Greenan, N. and Hamon-Cholet, S. (2001b), 'COI un Dispositif d'Enquêtes Couplées Employeurs / Employés sur les Changements Organisationnels et l'Informatisation. Tome 2 : Dictionnaire', processed Centre d'Etude de l'Emploi, Paris.

Greenan, N. and Mairesse, J. (1999),, 'Organisational Change in Manufacturing: What Do We Learn From Firm Representatives and From Their Employees?', NBER Working Paper 7285.

Holmes, T. J. (2002), 'The Role of Cities: Evidence from the Placement of Sales Offices', Federal Reserve Bank of Minneapolis Staff Report \#298 
Jaffe, A. B., Trajtenberg, M. and Henderson, R. (1993), 'Geographic Localization of Knowledge Spillovers as Evidenced by Patent Citations', Quarterly Journal of Economics, 108, pp. 577-598.

Jovanovic, B. and Rob, R. (1989), 'The Growth and Diffusion of Knowledge', Review of Economic Studies, 56, pp. 569-582.

Lucas, R. E. Jr, (1988), 'On The Mechanics of Economic Development', Journal of Monetary Economics, 22, pp. 3-42.

Lucas, R. E. Jr, (2001), 'Externalities and Cities', Review of Economic Dynamics, 4, pp. 245-274.

Manski, C. F. (1993), 'Identification of Endogenous Social Effects: The Reflection Problem', Review of Economic Studies, 60, pp. 531-542.

Marshall, A. (1890), Principles of Economics, Macmillan, London.

Moretti, E. (2000), 'Estimating the Social Return to Education: Evidence from Longitudinal and Cross-Sectional Data', processed UCLA.

Moretti, E. (2002), 'Human Capital Spillovers in Manufacturing: Evidence from Plant-Level Production Function', NBER Working Paper 9316.

Moretti, E. (2003), 'Human Capital Externalities in Cities', in J. V. Henderson and J. F. Thisse (eds), Handbook of Regional and Urban Economics, vol 4, North-Holland, Amsterdam, forthcoming.

Rauch, J. E. 1993, 'Productivity Gains from Geographic Concentration of Human Capital: Evidence from the Cities', Journal of Urban Economics, 34, pp. 380-400.

Rivera-Batiz, F. (1988), 'Increasing Returns, Monopolistic Competition, and Agglomeration Economies in Consumption and Production', Regional Science and Urban Economics, 18, pp. 125-153.

Roback, J. (1982), 'Wages, Rents, and the Quality of Life', Journal of Political Economy, 90, pp. $1257-1278$.

Rosenthal, S. S. and Strange, W. C. (2003), 'Microfoundations of Urban Increasing Returns: Empirical Evidence', in J. V. Henderson and J. F. Thisse (eds), Handbook of Regional and Urban Economics, vol 4, North-Holland, Amsterdam, forthcoming.

Saxenian, A. (1994), Regional Advantage, Harvard University Press, Cambridge (Mass.).

Simon, C. J. and Nardinelli, C. (2002), 'Human Capital and the Rise of American Cities, 1900-1990', Regional Science and Urban Economics, 32, pp. 59-96.

Storper, M. (1997), The Regional World: Territorial Development in a Global Economy, The Guilford Press, New York.

Topel, R. (1997), 'Factor Proportions and Relative Wages', Journal of Economic Perspectives 11, pp. 55-74. 


\section{CENTRE FOR ECONOMIC PERFORMANCE \\ Recent Discussion Papers}

591 Paul Willman

Alex Bryson

Rafael Gomez

590 Marco Manacorda

589 Alex Bryson

Rafael Gomez

588 Henry G. Overman

L. Alan Winters

587 Pierre-Philippe Combes Henry G. Overman

586 Henry G. Overman

585 A. B. Bernard

J. Bradford Jensen

P. K. Schott

584 A. B. Bernard

J. Bradford Jensen

P. K. Schott

583 S. Wood

S. Moore

582 T. Kirchmaier

581 C. Dougherty

$580 \quad$ S. Burgess

D. Mawson

579
S. Nickell
Why Do Voice Regimes Differ?

Childcare and the Labour Supply of Other Household Members: Evidence from 1920s America

Why Have Workers Stopped Joining Unions?

Trade Shocks and Industrial Location: the Impact of EEC Accession on the UK

The Spatial Distribution of Economic Activities in the European Union

Can We Learn Anything from Economic Geography Proper?

Falling Trade Costs, Heterogeneous Firms and Industry Dynamics

Survival of the Best Fit: Exposure to Low-Wage Countries and the (Uneven) Growth of U.S.

Manufacturing Plants

Reviewing the Statutory Union Recognition (ERA 1999)

Corporate Restructuring and Firm Performance of British and German Non-Financial Firms

Why Is the Rate of Return to Schooling Higher for Women than for Men?

Aggregate Growth and the Efficiency of Labour Reallocation

Poverty and Worklessness in Britain 
578 D. Marsden

577 S. Nickell

576 A. de Coulon

M. Piracha

575 H. Steedman

K. Wagner

J. Foreman

574 S. Gibbons

573 R. Griffith

S. Redding

H. Simpson

$572 \quad$ S. Redding

P. K. Schott

571 B. Petrongolo

C. A. Pissarides

570 M. Coles

B. Petrongolo

569 A. Bryson

L. Cappellari

C. Lucifora

568 A. Bryson

R. Gomez

567 M. Gutiérrez-Domènech

566 T. Kirchmaier
Renegotiating Performance: the Role of Performance Pay in Renegotiating the Effort Bargain

A Picture of European Unemployment: Success and Failure

Self-Selection and the Performance of Return

Migrants: the Source Country Perspective

The Impact on Firms of ICT Skill-Supply Strategies:

An Anglo-German Comparison

The Costs of Urban Property Crime

Productivity Convergence and Foreign Ownership at the Establishment Level

Distance, Skill Deepening and Development: Will Peripheral Countries Ever Get Rich?

Scale Effects in Markets with Search

A Test Between Unemployment Theories Using

Matching Data

Does Union Membership Really Reduce Job

Satisfaction?

Segmentation, Switching Costs and the Demand for Unionization in Britain

Employment After Motherhood: A European

Comparison

The Performance Effects of European Demergers 